\title{
Mitochondria as Potential Targets in Alzheimer Disease Therapy: An Update
}

\author{
Giovanna Cenini* and Wolfgang Voos \\ Institut für Biochemie und Molekularbiologie, Rheinische Friedrich-Wilhelms-Universität Bonn, Bonn, Germany
}

Alzheimer disease $(A D)$ is a progressive and deleterious neurodegenerative disorder that affects mostly the elderly population. At the moment, no effective treatments are available in the market, making the whole situation a compelling challenge for societies worldwide. Recently, novel mechanisms have been proposed to explain the etiology of this disease leading to the new concept that $A D$ is a multifactor pathology. Among others, the function of mitochondria has been considered as one of the intracellular processes severely compromised in $A D$ since the early stages and likely represents a common

\section{OPEN ACCESS}

Edited by: Cesare Mancuso, Catholic University of the Sacred Heart, Italy

Reviewed by: Amandine Grimm, University of Basel, Switzerland Cristina Carvalho, University of Coimbra, Portugal Sónia C. Correia, University of Coimbra, Portugal

${ }^{*}$ Correspondence: Giovanna Cenin gcenini@gmail.com

Specialty section: This article was submitted to Experimental Pharmacology and Drug Discovery, a section of the journal Frontiers in Pharmacology

Received: 10 April 2019

Accepted: 18 July 2019 Published: 23 August 2019

Citation:

Cenini $G$ and Voos W (2019) Mitochondria as Potential Targets in Alzheimer Disease

Therapy: An Update.

Front. Pharmacol. 10:902. doi: 10.3389/fphar.2019.00902 feature of many neurodegenerative diseases. Many mitochondrial parameters decline already during the aging, reaching an extensive functional failure concomitant with the onset of neurodegenerative conditions, although the exact timeline of these events is still unclear. Thereby, it is not surprising that mitochondria have been already considered as therapeutic targets in neurodegenerative diseases including AD. Together with an overview of the role of mitochondrial dysfunction, this review examines the pros and cons of the tested therapeutic approaches targeting mitochondria in the context of $A D$. Since mitochondrial therapies in AD have shown different degrees of progress, it is imperative to perform a detailed analysis of the significance of mitochondrial deterioration in $A D$ and of a pharmacological treatment at this level. This step would be very important for the field, as an effective drug treatment in $A D$ is still missing and new therapeutic concepts are urgently needed.

Keywords: Alzheimer disease, therapeutic strategy, mitochondria, mitochondrial dysfunction, mitochondrial therapy

\section{INTRODUCTION}

Alzheimer disease (AD) is a complex and heterogeneous disorder strongly affecting the cognitive functions and the memory of seniors.

Many risk factors were proposed to be significant contributors for the AD onset such as senescence, autophagy defects, genetic factors [i.e., ApolipoproteinaE-allele4 (APOE4), Triggering receptor expressed on myeloid cells 2 (Trem2)], microbiota alterations, lifestyle choices, cardiovascular and traumatic brain injury, as well as environmental factors (level of education, hypertension, obesity, diabetes, smoking, hearing loss, depression, physical inactivity, social isolation) (Livingston et al., 2017). It is now well accepted that important cellular pathways are compromised in AD. Together with intraneuronal neurofibrillary tangles (NFT) made of hyperphosphorylated tau protein and the extraneuronal senile plaques (SP) made of beta-amyloid (A $\beta$ ) peptides, synaptic failure, vascular 
damage, increased oxidative stress, neuronal and axonal injury, microglia-regulated neuroinflammation, and mitochondrial dysfunction are hallmarks of the disease (Figure 1).

Along the past years, $A \beta$ peptides have been considered one of the most promising therapeutic targets for AD. However, many clinical studies based on the A $\beta$ cascade hypothesis failed, and the idea that $A \beta$ pathology is not anymore the leading primary cause of AD has risen (Morris et al., 2018). Instead, nowadays the belief that $\mathrm{AD}$ is a multi-factorial disease is growing steadily, and mitochondrial dysfunction is one of the factors that may actively contribute to the disease onset and progression (Iturria-Medina et al., 2017; Veitch et al., 2019). Despite that, a logical temporal order of the events in $\mathrm{AD}$, as well as a valid and effective therapy, is still missing. However, our society urgently requires medical interventions to counteract this deleterious disease because of the severe negative impact on the quality of lives of the afflicted patients as well as on the health system as a whole due to a rapidly aging population.

This review focuses on the description of the role of mitochondrial dysfunction and the status of mitochondrial therapy in $\mathrm{AD}$. The main question addressed here is: could the mitochondrial organelle be a valid pharmacologic target to prevent or delay the $\mathrm{AD}$ onset or to block the $\mathrm{AD}$ progression?

\section{MITOCHONDRIA}

The mitochondrion is a cellular organelle with a characteristic and unique structure formed by two membranes, respectively called outer mitochondrial membrane (OMM) and inner mitochondrial membrane (IMM) that surround the matrix. Mitochondria are defined as the powerhouse of the cell because every cell in the human body relies on the energy provided by these organelles to sustain their vital functions. Mitochondrial energy production via the so-called process of oxidative phosphorylation takes place at the IMM through the activity of respiratory chain complexes (RCC), generating an inner membrane potential $(\mathrm{mt} \Delta \Psi)$ that is used by the ATP-synthase enzyme complex to synthesize adenosine triphosphate (ATP). This process depends on the supply of reducing equivalents by the end-oxidation of nutrients via the Krebs cycle or $\beta$-oxidation in the mitochondrial matrix compartment (Stock et al., 2000). Mitochondria contain their own DNA (mtDNA) located in the matrix that encodes mainly 13 protein subunits of the RCC. All other mitochondrial protein components are encoded in the nuclear DNA (nuDNA) and are imported into the organelle after the translation at cytosolic ribosomes. Hence, the maintenance of an entire and functional mitochondrial proteome requires a fine-tuned and well-coordinated sequence of many reactions and a close integration of organellar and cellular biogenesis processes (Pfanner et al., 2019).

Neurons are strictly dependent on the presence of mitochondria in particular at the synapses where these organelles produce ATP and buffer $\mathrm{Ca}^{2+}$-ion concentration, both fundamental processes for the implementation of neurotransmission and generation of membrane potential along the axon (Li et al., 2004; Verstreken et al., 2005; Gazit et al., 2016). This justifies the high amount of mitochondria at the synaptic area, higher than any other part of the neurons. Linked to that, a correct and efficient transport of neuronal mitochondria at the synaptic terminals is fundamental

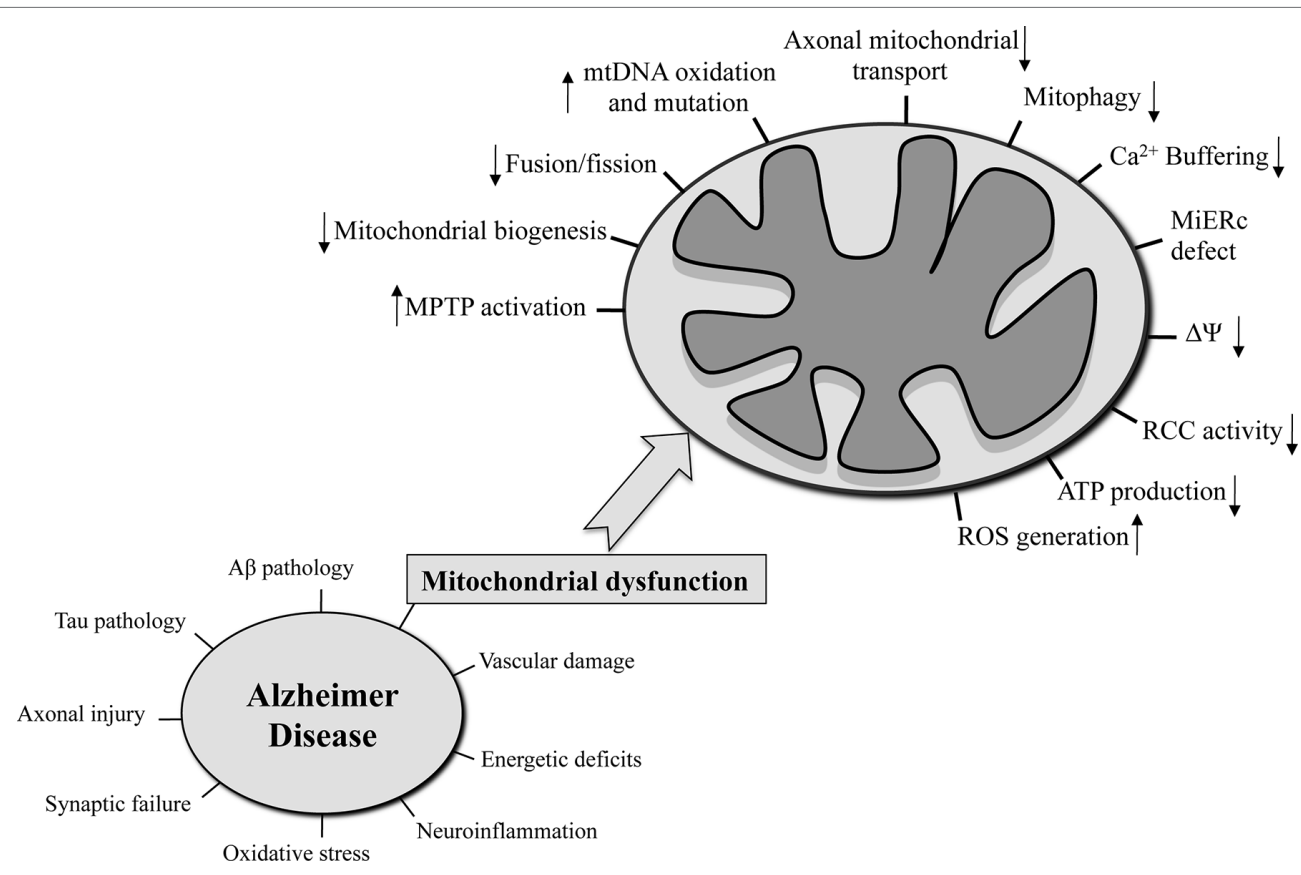

FIGURE 1 | The hallmarks that characterized $A D$ are reported in the left side of the figure. On the right side, the mitochondria-related functions that are seriously compromised in $A D$ are on focus. 
for their correct function. Both non-synaptic and synaptic mitochondria are usually synthesized in the neuronal soma and then transported in the other area of the neurons where they are required. The transport of mitochondria along the axons is guaranteed via microtubules and requires motor proteins such as kinesin, dynein, as well as the OMM protein Mitochondrial Rho GTPase (Miro). Axonal transport of mitochondria is also influenced by the metabolic demand and the $\mathrm{Ca}^{2+}$ status at the synaptic level (Yi et al., 2004; Glater et al., 2006; Russo et al., 2009; Sheng and Cai, 2012).

The enzymatic activity of the mitochondrial RCC results essentially in two "side effects." First, the generation of the $m t \Delta \Psi$ along the IMM is essential also for the execution of mitochondrial import of nuclear-encoded proteins and overall it is a parameter that reflects the health status of mitochondria and cells (Shariff et al., 2004). Second, a leakage of electrons from the RCC contributes significantly to the formation of reactive oxygen species (ROS). Therefore, ROS are considered a typical by-product of bioenergetic pathways (Quinlan et al., 2013). However, under normal physiological conditions, ROS production is well balanced by the presence of adequate antioxidant systems, and the damage to the diverse cellular constituents is contained. However, during aging, as well as during several pathological conditions, in particular in neurodegenerative diseases, this equilibrium becomes unbalanced. Increased ROS concentrations result in molecular damage at the site where they are produced or, through diffusion, in surrounding areas, leading to the generation of the so-called oxidative stress condition. ROS targets essentially comprise all cellular macromolecules, ranging from proteins, lipids, carbohydrates, up to nucleic acids (Cipak Gasparovic et al., 2017). The hippocampus region, the cortex, and more generally the brain are particularly vulnerable to oxidative stress because of their high consumption of oxygen and dependence on mitochondrial energy production. This susceptibility is increased by low levels of antioxidant defenses and a high content of polyunsaturated fats, which are especially vulnerable to oxidative alterations (Cobley et al., 2018).

Mitochondria form a dynamic tubular network extended throughout the cytosol, a behavior that is often misrepresented by the cell biology textbooks. Two crucial processes, fusion and fission, regulate the entire morphology and structure of this mitochondrial network (Mishra and Chan, 2016). During the fission reaction, a part of the mitochondrial tubule is divided into fragments, a process that is regulated by a member of the dynamin family, Dynamin-1-like protein (Drp1), together with the OMM fission factors Mitochondrial fission 1 protein (Fis1) and Mitochondrial dynamics protein MID49 [Mitochondrial elongation factor 2 (MIEF2)]. Fusion, where two or more pieces of mitochondria are fused together to one structure, happens through joint activity of the proteins Dynamin-like $120 \mathrm{kDa}$ protein [or Optic atrophy protein 1 (OPA1)] and Mitofusin 1 and 2 (Mfn1 and Mfn2). Fusion/fission processes together with the precursor proteins import and internal proteins translation are part of the mitochondrial biogenesis in which the cells increase their mitochondrial mass (Sanchis-Gomar et al., 2014). A master regulator of mitochondrial biogenesis is Peroxisomeproliferator-activated receptor $\gamma$ coactivator-1 $\alpha$ (PGC-1 $\alpha$ )
(Scarpulla, 2011) that activates a series of transcriptional factors, including the Mitochondrial transcription factor A (TFAM), which regulates transcription and replication of mtDNA (Kang et al., 2018), and Nuclear respiratory factor 1 (NFR-1) and 2 (NFR-2), which control the mitochondrial protein-encoded nuclear genes (Scarpulla, 2011).

The buffer of intracellular $\mathrm{Ca}^{2+}$ is mediated mainly by the cooperation between endoplasmic reticulum (ER) and mitochondria through the formation of contact sites (Krols et al., 2016) that permit the $\mathrm{Ca}^{2+}$ uptake from the cytosol and the exchange of the ion between the two organelles (Rizzuto and Pozzan, 2006). $\mathrm{Ca}^{2+}$ regulates important mitochondrial metabolic enzymes (McCormack et al., 1990). The mitochondria contain two types of $\mathrm{Ca}^{2+}$ channels: the Mitochondria calcium uniporter (MCU) with high selectivity for this ion and localized in the IMM (De Stefani et al., 2011) and the Voltage-dependent anion channel (VDAC) localized in the OMM that regulates the release of the $\mathrm{Ca}^{2+}$ from the mitochondria (Krols et al., 2016). Furthermore, VDAC cooperates with the adenine nucleotide transporter in the IMM and the cyclophin D (CypD) in the matrix on the formation of the mitochondrial permeability transition pore (mPTP) (Bernardi, 1999). An mPTP opening leads to activation of apoptosis and then cell death (Green and Kroemer, 2004). As already mentioned above, at the synaptic level, mitochondria regulate the amount of $\mathrm{Ca}^{2+}$ fundamental for neurotransmission and in general for the exertion of synaptic functions (Werth and Thayer, 1994; Billups and Forsythe, 2002).

Mitochondrial functions and eventually cellular homeostasis are guaranteed by a dedicated mitochondrial quality control system (mtQCS). The mtQCS comprises a multitude of different biochemical mechanisms that act at different levels, affecting individual polypeptides as well as the whole organelle. While the folding state and activities of mitochondrial proteins are controlled by endogenous chaperones and proteases (Voos, 2013), damaged mitochondria may be removed by a selective autophagy pathway, termed mitophagy (Youle and Narendra, 2011). The primary regulator of the mitophagy is a specialized signaling system consisting of the protein PTEN-induced kinase 1 (Pink1) and the ubiquitin ligase Parkin that is activated after the loss of $m t \Delta \Psi$ (Rüb et al., 2017). An accumulation of Pink1 at the OMM of damaged mitochondria is thought to recruit Parkin that leads to a labeling of the mitochondria for the subsequent mitophagy process. This is followed by the formation of an autophagosomal membrane engulfing the mitochondria followed by its fusion with the lysosomes where ultimately the digestion of the mitochondrial material takes place.

\section{MITOCHONDRIAL DYSFUNCTION IN AD}

In $\mathrm{AD}$ brain, the alteration of energetic pathways, also linked to the reduction of glucose consumption, is a well-established feature of the disease (Gibson and Shi, 2010). The glucose uptake in the brain is usually measured with the positron emission tomography (PET) tracer 18-fluorodeoxyglucose (fDG). In subjects with $\mathrm{AD}$, PET studies have consistently demonstrated a low rate of glucose metabolism (between $20 \%$ and $30 \%$ 
lower than healthy individuals) in brain regions involved in processing memory (e.g., the hippocampus, posterior cingulate, temporal, and parietal lobes) (Kapogiannis and Mattson, 2011). Furthermore, it was proposed that the metabolic changes appeared earlier than the onset of the histopathological markers and symptoms (Gibson and Shi, 2010). Although the real cause is still unclear, the defective metabolism that characterizes $\mathrm{AD}$ could be easily linked to mitochondrial dysfunction.

Since its formulation in 1992 (Hardy and Higgins, 1992), the "amyloid cascade hypothesis" has dominated the AD field in the past 30 years. This hypothesis was based on two clear evidences: $A \beta$ peptides constitute the extraneuronal senile plaques and mutation of $\mathrm{A} \beta$ peptides precursor, amyloid- $\beta$ precursor protein (APP), leads to an early onset of AD. However, due to the fails in all Phase III clinical trials in human $A D$, this hypothesis has substantially lost ground and needed to be strongly revised or integrated with other hypotheses (Karran et al., 2011). In 2004, a new hypothesis was proposed to explain the onset of sporadic AD. The hypothesis, called "mitochondrial cascade hypothesis," described that each human genetic heritage influences mitochondrial functions with a primary repercussion on the onset of $\mathrm{AD}$ pathology. In other words, according to this hypothesis, the mitochondrial dysfunction is the primary process to trigger all the cascade of events that lead to sporadic late-onset AD (Swerdlow and Khan, 2004; Swerdlow et al., 2014).

Despite the fact that the validity of the mitochondrial cascade hypothesis has yet to be demonstrated in different $\mathrm{AD}$ models as well as human patients, the following mitochondrial functions were found severely compromised in the $\mathrm{AD}$ context (Hauptmann et al., 2009): mitochondrial morphology (Johnson and Blum, 1970) and number (Hirai et al., 2001), oxidative phosphorylation, $\mathrm{mt} \Delta \Psi, \mathrm{Ca}^{2+}$ buffering, ROS production (Butterfield and Halliwell, 2019), mtDNA oxidation and mutation (Wang et al., 2006), mitochondrial-ER contact sites (Area-Gomez et al., 2018), mitochondrial biogenesis, mitochondrial transport along the neuronal axon (Calkins and Reddy, 2011), and mitophagy (Figure 1). In a neuronal context, any of these dysfunctional processes could lead to synaptic deficits and critical consequences not only for single neurons but also for a more complex structure like the brain (Cai and Tammineni, 2017).

In $\mathrm{AD}$ brains, the activities of the enzymes involved in mitochondrial energy production, such as complex IV cytochrome c oxidase (COX), pyruvate dehydrogenase complex, mitochondrial isocitrate dehydrogenase, $a$-ketoglutarate dehydrogenase ( $\mathrm{aKGDH}$ ), and ATP synthase complex were found decreased, while the succinate dehydrogenase (complex II) and malate dehydrogenase activities were increased (Maurer et al., 2000; Cardoso et al., 2004; Gibson and Shi, 2010; Wojsiat et al., 2015). This definitely compromises the maintenance of the mt $\Delta \Psi$ and eventually of the mitochondrial ATP production (Beck et al., 2016).

In line with that, the imbalance between ROS production and antioxidant power was observed in $\mathrm{AD}$ brains, cerebrospinal fluid (CSF), and blood (García-Blanco et al., 2017). Since the 1990s, the ROS-induced oxidative stress has received considerable attention as one of the main factors contributing to the $\mathrm{AD}$ pathogenesis (Mark et al., 1997). Already the mild cognitive impairment
(MCI), an early stage in the AD chronology, is characterized by the significant increase of oxidative stress markers, such as lipid peroxidation and protein oxidation products, and the decrease of antioxidants in the brain and peripheral compartments (Praticò et al., 2002; Rinaldi et al., 2003; Butterfield et al., 2006).

The analysis of the samples from different $\mathrm{AD}$ experimental models and $\mathrm{AD}$ patients showed a strong link between the oxidative stress and mitochondrial dysfunction. In the transgenic mice over-expressing human APP (Tg mAPP mice), an early and progressive accumulation of $A \beta$ peptide in synaptic mitochondria led to a mitochondrial synaptic dysfunction such as damaged mitochondrial respiratory activity, increased mPTP and oxidative stress, and impaired mitochondrial axonal transport (Du et al., 2010). Data from the 3xTg-AD mice showed that the compromised mitochondria bioenergetics together with elevated oxidative stress levels are early phenomena appearing before the development of observable A $\beta$ plaques (Hauptmann et al., 2009; Yao et al., 2009). Oxidation of one of the mitochondrial enzymes involved in the oxidative phosphorylation, ATP synthase, was found in isolated lymphocytes from $\mathrm{AD}$ peripheral blood as well as in MCI and AD brains (Sultana et al., 2006; Reed et al., 2008; Tramutola et al., 2018). This may explain the compromised activity of the ATP synthase and the reduction of ATP levels in $\mathrm{AD}$. Another paper showed a correlation between the reduction of the mitochondrial enzyme Aconitase (ACO2) activity and the plasma antioxidant levels in peripheral lymphocytes from $\mathrm{MCI}$ and $\mathrm{AD}$ patients proving again the strong association between the oxidative stress and the mitochondrial dysfunction in AD (Mangialasche et al., 2015). Interestingly, the new and innovative technology for $\mathrm{AD}$ modeling obtained with the human induced pluripotent stem cells (iPSCs) directly from AD patients demonstrated further that $\mathrm{AD}$-relevant mitochondrial aberrations, including oxidative stress, have a causative role in the developments of the disease. Indeed, neurons and astrocytes from AD-iPSCs presented increased ROS production and RCC levels and enhanced susceptibility to the stressors (Ochalek et al., 2017; Oksanen et al., 2017; Birnbaum et al., 2018).

The mitochondrial dynamics such as fusion and fission processes were found unbalanced in $\mathrm{AD}$, potentially leading to i) compromised distribution and morphology of mitochondria in the neurons (Hirai et al., 2001) and ii) fragmented mitochondria observed in fibroblasts and brains from AD patients (Wang et al., 2008a; Wang et al., 2009). The mitochondrial fusion and fission proteins were differentially expressed in AD hippocampus with an increase of the mitochondrial fission protein Fis1 alongside with a significant downregulation of Drp1 and fusion proteins Mfn1, Mfn2, and OPA1 (Wang et al., 2009). Similar results were found in a AD cybrids model, together with bleb likeand shorter mitochondria compared to control samples (Gan et al., 2014). Furthermore, increased phosphorylation at Ser 616 site and S-nitrosylation of Drp1, which both facilitate the mitochondrial fission (Taguchi et al., 2007; Cho et al., 2009), were higher in a $\mathrm{AD}$ brains compared to control (Wang et al., 2009). Beside that, the protein Drp1 was seen interacting with $\mathrm{A} \beta$ and phosphorylated tau in brain homogenates from $\mathrm{AD}$ patients (Manczak et al., 2011; Manczak and Reddy, 2012). A recent study performed in samples from $\mathrm{AD}$ and healthy control 
subjects showed the significant association between a specific polymorphism in MFN2 gene and AD suggesting that genetic polymorphism of fusion process regulation might be involved in the AD pathogenesis (Kim et al., 2017). In addition, mfn2 protein act as a tether between mitochondria and ER membranes (de Brito and Scorrano, 2008). In this regard, $\mathrm{mfn} 2$ influences the Presenilin 2 (PS2), whose mutation is linked to the familial AD (FAD), in the modulation of the mitochondria-ER contact sites (Filadi et al., 2016).

Several experimental AD models linked to APP overexpression or $\mathrm{A} \beta$ peptides treatments are characterized as well by mitochondrial fragmentation and abnormal mitochondrial distribution along the neurons due to an alteration of mitochondrial fusion and fission proteins levels (Wang et al., 2008b; Du et al., 2010; Zhao et al., 2010; Calkins and Reddy, 2011; Wang et al., 2017). All these results lead to two critical remarks: i) the altered balance between fusion and fission that interferes with mitochondrial transport contributes actively to the $\mathrm{AD}$ pathogenesis and ii) the mitochondrial dynamics impairment could be a new therapeutic target in $\mathrm{AD}$.

Another key mitochondrial function, the mitochondrial biogenesis, was impaired in $\mathrm{AD}$. The significant reduction of the number of mitochondria in $\mathrm{AD}$ human hippocampus and in cell culture models already suggests that the mitochondrial biogenesis is compromised (Hirai et al., 2001; Wang et al., 2008b). Furthermore, the level of protein regulating the mitochondrial biogenesis such as PGC-1a, NRF1 and 2, and TFAM was significantly reduced in human $\mathrm{AD}$ hippocampus and cellular models overexpressing APP Swedish mutation (Qin et al., 2009; Sheng et al., 2012). In the AD mouse model harboring mutant human transgenes of APP and Presenilin-1 (PS1), the mitochondrial biogenesis markers were found again declined in particular in the hippocampus region, and the use of melatonin brought beneficial effects (Song et al., 2018).

Interestingly, on one side, mitophagy was able to reverse the memory impairment, to prevent the cognitive deterioration and the $\mathrm{A} \beta$ peptide/tau pathology in several $\mathrm{AD}$ models (Fang et al., 2019). However, on the other side, mitophagy was also strongly affected in $\mathrm{AD}$, leading to the accumulation of damaged mitochondria and consequently to dysfunctional neurons. One cause may be the impairment of the fusion between the autophagosome and lysosomes. This was observed in cultured cells overexpressing mutant APP, in AD mouse models, and also in neurons from AD patients' brain (Boland et al., 2008; Lee et al., 2010; Coffey et al., 2014). In AD brains, the somatic mutations found in mtDNA are higher than in healthy brains, potentially triggering other neuropathological consequences such as the increased ROS production in neurons and the promotion of amyloidogenic processing of APP (Lin et al., 2002).

The two major and typical histopathological markers of $\mathrm{AD}$, $\mathrm{A} \beta$ peptide and tau, harmfully accumulate in or interact nonspecifically with mitochondria (Eckert et al., 2010). A $\beta$ peptide and abnormal tau negatively affect axonal transport and consequently the transport of mitochondria along the axon from the neuronal soma to the synapses. $\mathrm{AD}$ mouse models, overexpressing $\mathrm{A} \beta$ peptides, have damaged mitochondria usually characterized by impaired axonal transport of mitochondria, a reduced $\operatorname{mt} \Delta \Psi$, and inhibited RCC with a compromised ATP production (Rui et al., 2006). The accumulation of $A \beta$ peptides or of the precursor APP inside the mitochondria (Anandatheerthavarada et al., 2003; Hansson Petersen et al., 2008) and even the interaction of $\mathrm{A} \beta$ peptides with some component of the mitochondrial matrix (Lustbader et al., 2004) would be the most straightforward and rational explanations to justify the mitochondrial dysfunctions in the animal models of AD. However, mitochondria lack APP and the set of the enzymes required for $A \beta$ peptide generation, making a mitochondria-localized production of $\mathrm{A} \beta$ peptides unlikely. Furthermore, a solid mechanism that explains the mitochondrial import of $A \beta$ peptides and the direct negative effects of $A \beta$ peptides on mitochondria is still missing, suggesting that the mitochondrial dysfunctions identified in all these $\mathrm{AD}$ models are indirect effects of $A \beta$ peptides. In support of this point, a recent study showed that $A \beta$ peptides impaired mitochondrial import of nuclear-encoded precursor proteins due to an extra mitochondrial co-aggregation process (Cenini et al., 2016).

Tauopathies including AD are also characterized by mitochondrial dysfunction. Tau influences, directly and indirectly, the mitochondrial transport along the neuronal axon and the mitochondrial functions. This leads to the reduction and impairment of mitochondria at the presynaptic terminals with obvious deleterious consequences (Dubey et al., 2008; DuBoff et al., 2012). In AD brains, phosphorylated tau was found interacting with VDAC1 leading as well to mitochondrial dysfunction (Manczak and Reddy, 2012). Hyperphosphorylation of tau negatively affects complex I activity with a decrease of ATP production, an increase of oxidative stress, dissipation of $\mathrm{mt} \Delta \Psi$, induction of the mitochondrial fission, and excessive mitochondrial fragmentation in postmortem brains from $\mathrm{AD}$ patients and in murine models (Manczak et al., 2011; Eckert et al., 2014). In addition, mitochondrial stress was shown to promote tau-hyperphosphorylation in a mouse model (Melov et al., 2007). These observations argue for a prominent role of tau pathology in the mitochondrial dysfunction of $\mathrm{AD}$.

The Translocase of outer membrane $40 \mathrm{kDa}$ submit homolog (Tomm40) is a mitochondrial channel localized in OMM that is fundamental for the import of nuclear-encoded mitochondrial preproteins (Chacinska et al., 2009). A $\beta$ peptides affected directly or indirectly the mitochondrial import machinery including Tomm40, and this may also contribute to the mitochondrial dysfunction observed in AD (Devi et al., 2006; Anandatheerthavarada and Devi, 2007; Cenini et al., 2016). TOMM40 gene is contained in a tight gene cluster together with APOE gene in the chromosome 19 (Gottschalk et al., 2014; Subramanian et al., 2017). APOE is one of the most significant genetic risk factors for late-onset sporadic $\mathrm{AD}$ (LOAD) with the $\varepsilon 4 / \varepsilon 4$ isoform linked to the highest risk (Saunders et al., 1993). It seems that also a variable-length, deoxythymidine homopolymer polymorphism in intron 6 of the TOMM40 gene represents a genetic risk for LOAD. However, different groups showed that TOMM40 SNPs (single-nucleotide polymorphisms) are associated with the LOAD (Martin et al., 2000; Takei et al., 2009; Kim et al., 2011; Davies et al., 2014). In a Caucasian ethnic group three variants of the TOMM40 polymorphisms were identified, 
and the variant rs 10524523 has received particular attention since it lowered the age of LOAD onset by 7 years in APOE3/4 carriers (Roses et al., 2010). Furthermore, this variant was associated with impaired cognition and the gray matter volume in the brain area susceptible to AD (Johnson et al., 2011). Different groups also demonstrated the strong influence of TOMM40 “523" variant on TOMM40 and APOE genes transcription (Linnertz et al., 2014; Payton et al., 2016).

The integration of all these facts into a significant biological context like neuronal cells in $\mathrm{AD}$, suggests that the accumulation of dysfunctional mitochondria at the synapses and the lack of their replacement would contribute substantially to the neurons degeneration and consequently to the worsening of the AD condition.

\section{MITOCHONDRIAL THERAPIES IN AD}

$\mathrm{AD}$ is still without a cure and also essentially lacks a rational understanding of the primary event triggering the disease. Nevertheless, an improved comprehension of this deleterious disorder and the development of effective treatments are essential not only to heal the disease but also eventually to prevent or postpone the onset of the symptoms in the patients.

The traditional cures used nowadays to treat the $\mathrm{AD}$ patients are so far the cholinesterase inhibitors (donepezil, rivastigmine, and galantamine) and memantine that block the N-methyl-Daspartate (NMDA) receptor and the excess of glutamate activity. NMDA receptors and acetylcholin (Ach) are fundamental in memory and learning processes and their concentration and function are compromised in AD (Francis, 2005). However, these treatments improve the cognitive and memory functions, without really slowing down the progression of the disease.

As described above, mitochondrial dysfunctions and a compromised energetic metabolism are two prominent aspects of AD pathology. Therefore, mitochondria should be seriously considered as pharmacological targets. In the course of history, nevertheless, different compounds affecting mitochondria were already tested in $\mathrm{AD}$ without a successful outcome. However, as the idea of $\mathrm{AD}$ as a multifactorial disease gained more ground in the last years, a reconsideration of mitochondria as a valid therapeutic target together with other medications is strongly recommended.

Mitochondria could be targeted through two ways: i) by pharmacologic approaches acting on mitochondria directly or ii) by action on the lifestyle that indirectly hits this organelle (Figure 2). In the following section, we describe the most popular mitochondrial treatments that have been used until today on AD patients, and in Table 1, we summarize specifically the beneficial effects of these compounds on mitochondria in different experimental AD models. The table is also a proof that these treatments are able to act effectively and positively on mitochondria, and therefore a revision and improvement of their use in $\mathrm{AD}$ would be worthy.

More information about the ongoing clinical trials concerning mitochondria in $\mathrm{AD}$ are summarized in Wilkins et al. and in Perez Ortiz et al. (Perez Ortiz and Swerdlow, 2019; Wilkins and Morris, 2017), and they can also be found in www. clinicaltrials.gov.

\section{Antioxidants}

Since the increased oxidative stress accompanied by the reduction of the antioxidant power was measured in the brain, CSF, and blood from AD patients, treatments with antioxidant compounds were tested to counteract this oxidative unbalance and slow down the progression of the $\mathrm{AD}$ symptoms.

Typical antioxidants were the vitamins, $\mathbf{E}$ and $\mathbf{C}$, but their effects in the context of $\mathrm{AD}$ remain questionable. For example, in two studies with vitamin E, some markers of lipid peroxidation were found decreased in $\mathrm{AD}$ patients' CSF, with no consistent effect on or even a deterioration of cognitive functions (Arlt et al., 2012; Galasko et al., 2012). Vitamin E was also administered in combination with selenium. However, high levels of selenium were found toxic with a pro-oxidant effect, glial activation, and neuronal death (Vinceti et al., 2014). There is an important study called PREADViSE that was performed to see the longterm effect of anti-oxidant supplements (Vitamin E, selenium, Vitamin E + selenium or placebo) on dementia incidence among asymptomatic men. However, the supplement did not prevent dementia occurrence (Kryscio et al., 2017).

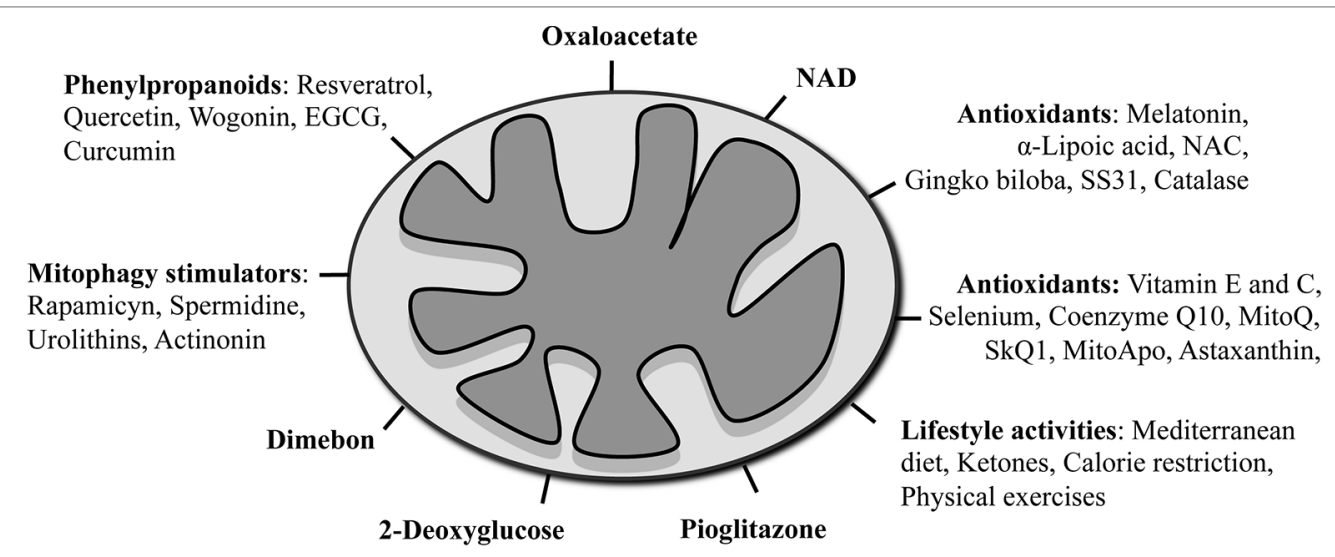

FIGURE 2 | Schematic summary of mitochondrial-targeted therapies used in AD models and clinical trials. 
TABLE 1 | List of compounds and lifestyle activities effects on mitochondria in experimental models for AD.

\begin{tabular}{|c|c|c|c|}
\hline Treatment & Effect on mitochondria & Experimental AD models & References \\
\hline \multicolumn{4}{|l|}{ Antioxidants } \\
\hline Vitamin $E$ & $\begin{array}{l}\text { Increase mt } \triangle \Psi \text { and ATP } \\
\text { ROS scavenger } \\
\text { Reduction of lipid peroxidation }\end{array}$ & $\begin{array}{l}\text { In vitro glutamate-injured astrocytes } \\
\text { In vivo aged old mice }\end{array}$ & $\begin{array}{l}\text { (Selvaraju et al., 2014; } \\
\text { Schloesser et al., 2015) }\end{array}$ \\
\hline Selenium & $\begin{array}{l}\text { Inhibition of ROS production and oxidative damage } \\
\text { Reduction of mitochondrial membrane depolarization }\end{array}$ & $\begin{array}{l}\text { In vitro } \mathrm{A} \beta_{42}-\mathrm{CFP} \text {-overexpressed HEK293 } \\
\text { cell line } \\
\text { In vivo scopolamine-treated aged rats }\end{array}$ & $\begin{array}{l}\text { (Chen et al., 2013; Balaban } \\
\text { et al., 2017) }\end{array}$ \\
\hline Vitamin C & $\begin{array}{l}\text { Maintenance of mitochondrial integrity through reduction } \\
\text { of oxidative damage } \\
\text { Reduction of mitochondrial membrane depolarization and } \\
\text { mitochondria-mediated apoptosis }\end{array}$ & $\begin{array}{l}\text { In vitro } \mathrm{A} \beta_{1-42} \text { peptide-treated human cortical } \\
\text { neurons } \\
\text { In vivo } 5 \text { XFAD Tg mice } \\
\text { In vivo APP/PSEN1 mice }\end{array}$ & $\begin{array}{l}\text { (Medina et al., 2002; Kook } \\
\text { et al., 2014; Dixit et al., 2017) }\end{array}$ \\
\hline Coenzyme Q10 & $\begin{array}{l}\text { Attenuation of decreased oxidative phosphorylation } \\
\text { efficiency and of increased } \mathrm{H}_{2} \mathrm{O}_{2} \text { production } \\
\text { Reduction of mitochondrial accumulation of } A \beta \text { peptide } \\
\text { Prevention of } \mathrm{A} \beta \text { peptide-induced mPTP opening } \\
\text { Protection against dissipation of } \mathrm{mt} \triangle \Psi \\
\text { Beneficial effect of mitochondrial ETC }\end{array}$ & $\begin{array}{l}\text { Isolated mitochondria from } A \beta_{1-40} \text { peptide- } \\
\text { treated diabetic Goto-Kakizaki aged rats } \\
\text { In vitro } A \beta_{25-35} \text { peptide-treated HUVEC cell line } \\
\text { In vitro } A \beta_{1-42} \text { peptide-treated M17 cell line } \\
\text { In vivo TgP301S mice } \\
\text { In vivo Tg19959 mice }\end{array}$ & $\begin{array}{l}\text { (Moreira et al., 2005; Dumont } \\
\text { et al., 2011; Elipenahli et al., } \\
\text { 2012; Sadli et al., 2013; Durán- } \\
\text { Prado et al., 2014) }\end{array}$ \\
\hline $\begin{array}{l}\text { Mitoquinone } \\
\text { (MitoQ) }\end{array}$ & $\begin{array}{l}\text { Prevention of increased ROS production, loss of mt } \triangle \Psi \text {, } \\
\text { decreased GSH/GSSG ratio, increased MDA and 3-NT } \\
\text { Regulation of mitochondrial fusion, fission, and matrix } \\
\text { genes } \\
\text { Protection of mitochondrial structure } \\
\text { Amelioration of ATP production, COX activity, and } \\
\text { depletion of the cardiolipin }\end{array}$ & $\begin{array}{l}\text { In vitro } \mathrm{A} \beta_{22-35} \text { peptide-treated mouse cortical } \\
\text { neurons and } \mathrm{N} 2 \mathrm{a} \text { cell line } \\
\text { In vivo } 3 \times \mathrm{Tg}-\mathrm{AD} \text { and Tg2576 mice } \\
\text { In vivo human } \mathrm{A} \beta \text {-overexpressed } C \text {. elegans }\end{array}$ & $\begin{array}{l}\text { (Manczak et al., 2010; } \\
\text { McManus et al., 2011; Ng } \\
\text { et al., 2014) }\end{array}$ \\
\hline SkQ1 & $\begin{array}{l}\text { Preservation of mitochondrial structure } \\
\text { Improvement of mitochondrial biogenesis } \\
\text { Increase of COX activity } \\
\text { Inhibition of ROS production } \\
\text { Reduction of mtDNA deletion }\end{array}$ & In vivo OXYS rats & $\begin{array}{l}\text { (Loshchenova et al., 2015; } \\
\text { Stefanova et al., 2016; } \\
\text { Kolosova et al., 2017) }\end{array}$ \\
\hline $\begin{array}{l}\text { MitoApo or } \\
\text { apocynin }\end{array}$ & $\begin{array}{l}\text { Protection against oxidative stress-induced cell death } \\
\text { Reduction of superoxide production }\end{array}$ & In vitro 6-OHDA-treated LUHMES cell line & (Brenza et al., 2017) \\
\hline Astaxanthin & Prevention of mitochondrial $\mathrm{H}_{2} \mathrm{O}_{2}$ production & $\begin{array}{l}\text { In vitro } A \beta_{1-42} \text { oligomers-treated mouse } \\
\text { hippocampal neurons }\end{array}$ & (Lobos et al., 2016) \\
\hline Melatonin & $\begin{array}{l}\text { Restoration of: respiration rate, RCC proteins expression, } \\
\mathrm{mt} \triangle \Psi \text {, ROS production, ATP levels } \\
\text { Prevention of decreased mitochondrial volume } \\
\text { Improvement of mitochondrial biogenesis factors } \\
\text { expression and mtDNA/nuDNA ratio } \\
\text { Amelioration of mitochondrial membrane fluidity and } \\
\text { mitochondrial structure } \\
\text { Stabilization of cardiolipin and mPTP } \\
\text { Decrease of mitochondrial } \mathrm{Ca}^{2+} \text { levels }\end{array}$ & $\begin{array}{l}\text { Isolated mitochondria from APPswe and APP/ } \\
\text { PSEN1 mice } \\
\text { In vitro APPswe-overexpressed HEK293 cell } \\
\text { line } \\
\text { In vitro } \mathrm{A} \beta_{22-35} \text { peptide-treated cultured rat } \\
\text { hippocampal neurons } \\
\text { In vitro A } \beta \text { peptide-treated NARP cybrids cell } \\
\text { line } \\
\text { In vivo OXYS rats } \\
\text { In vivo injection of } A \beta_{1-42} \text { peptide in rats } \\
\text { hippocampus } \\
\text { In vivo APP/PSEN1 mice }\end{array}$ & $\begin{array}{l}\text { (Dong et al., 2010; Dragicevic } \\
\text { et al., 2011a; Dragicevic } \\
\text { et al., 2012; Peng et al., } \\
\text { 2012; Rosales-Corral et al., } \\
\text { 2012b; Gerenu et al., 2015; } \\
\text { Rudnitskaya et al., 2015; Wang } \\
\text { et al., 2019) }\end{array}$ \\
\hline$\alpha$-Lipoic acid (LA) & $\begin{array}{l}\text { Decrease of oxidative stress and apoptotic markers } \\
\text { Preservation of COX assembly } \\
\text { Elevation of ATP levels, Krebs cycle dehydrogenase, } \\
\text { complex I, and COX activities }\end{array}$ & $\begin{array}{l}\text { In vitro } \mathrm{AD} \text { fibroblast } \\
\text { In vivo aged rats } \\
\text { In vitro } \mathrm{A} \beta_{1-42} \text { peptide-treated differentiated } \\
\mathrm{SH} \text {-SY } 5 Y \text { cell line } \\
\text { In vivo ApoE4 } \mathrm{Tg} \text { mice }\end{array}$ & $\begin{array}{l}\text { (Moreira et al., 2007; Ajith } \\
\text { et al., 2014; Marinelli et al., } \\
\text { 2017) }\end{array}$ \\
\hline $\begin{array}{l}\text { N-Acetyl-cysteine } \\
\text { (NAC) }\end{array}$ & $\begin{array}{l}\text { Decrease oxidative stress and apoptotic markers } \\
\text { Preservation of COX assembly }\end{array}$ & In vitro $\mathrm{AD}$ fibroblast & (Moreira et al., 2007) \\
\hline Ginkgo biloba & $\begin{array}{l}\text { Stabilization of } \mathrm{mt} \triangle \Psi \text { and ATP production } \\
\text { Reduction of ROS/RNS production } \\
\text { Increase of mitochondrial APE1 levels } \\
\text { Enhancement of complex I, III, COX activities } \\
\text { Improvement of oxygen consumption } \\
\text { Up-regulation of mitochondrial DNA } \\
\text { Block of mitochondria-mediated apoptosis }\end{array}$ & $\begin{array}{l}\text { In vitro APPmutant-overexpressed and } \mathrm{A} \beta \\
\text { peptide-treated PC12 cell line } \\
\text { In vitro } \mathrm{A} \beta_{25-35} \text { peptide-treated IMR-32 and } \\
\mathrm{SH}-\mathrm{SY} 5 \mathrm{Y} \text { cell line } \\
\text { In vitro } \mathrm{APP}-\text {-overexpressed } \mathrm{SH}-\mathrm{SY} 5 \mathrm{Y} \text { cell line } \\
\text { In vivo } \mathrm{A} \beta_{25-35} \text { peptide-injected rats }\end{array}$ & $\begin{array}{l}\text { (Eckert et al., 2003; Eckert } \\
\text { et al., 2005; Rhein et al., 2010; } \\
\text { Tian et al., 2013; Kaur et al., } \\
\text { 2015) }\end{array}$ \\
\hline
\end{tabular}


TABLE 1 | Continued

\begin{tabular}{ll}
\hline Treatment & Effect on mitochondria \\
\hline $\begin{array}{l}\text { Szeto-Schiller } \\
\text { tetrapeptides } 31\end{array}$ & $\begin{array}{l}\text { Increase of mitochondrial biogenesis and dynamics } \\
\text { (SS31) }\end{array}$ \\
& Rroteins level \\
& Rescue of mitochondrial anterograde transport \\
& peroxidation levels \\
& Prevention of mPTP, mitochondrial swelling, and \\
& mitochondria-mediated apoptosis \\
& Protection of mitochondrial structure \\
& Increase of ATP production and supply at nerve terminals \\
& Increase of COX activity, and mt $\triangle \Psi$ \\
& Increase of mtDNA copy number and mitochondrial \\
& network \\
& Reduction of abnormal APP process, oligomeric A $\beta$ \\
& peptides, and BACE1 activity and levels, and oxidative \\
& damage \\
Increase of protective soluble APP $\alpha$ and CTF83 fragments
\end{tabular}

\section{Phenylpropanoids \\ Resveratrol}

Quercetin

Wogonin

Epigallocatechin-3gallate (EGCG)
Attenuation of ROS accumulation, $\mathrm{mt} \triangle \Psi$, and mitochondria-mediated apoptosis

Increase of COX levels

Stimulation of mitophagy/autophagy

Restoration of $\mathrm{mt} \triangle \Psi$, ROS production, and ATP levels, and the normal mitochondrial morphology

Increase MnSOD activity

Prevention of mitochondria-mediated apoptosis

Rescue the mt $\triangle \Psi$ loss

Attenuation of mitochondria-mediated apoptosis

Attenuation of ROS accumulation

Increase of MnSOD level

Restoration of altered $m t \Delta \Psi_{t}$, ATP levels, and

mitochondria respiratory rates

Curcumin
Increase of ATP levels and COX activity

Positive effect on $\mathrm{mt} \triangle \Psi$ and respiratory control ratio

Reduction of ROS production and mitochondria-mediated apoptosis

Restoration of complex I, II, COX levels and activities

\section{Action of the life style}

Calories restriction

Oleuropein

aglycone (OLE)

Hydroxytyrosol

(HT)

Ketones

Physical exercise (PE)
Decrease of $F_{0} F_{1}$-ATPase activity

Stimulation of mitophagy/autophagy

Reduction of mitochondrial carbonyl protein

ROS scavenger

Enhancement of MnSOD level

Increase of TCA cycle intermediates and ATP hydrolysis

Reduction of mitochondrial redox potential (free mitochondrial $\left[\mathrm{NAD}^{+}\right] /[\mathrm{NADH}]$ ratio oxidation)

Increase of mitochondrial mass, $\mathrm{mt} \triangle \Psi$, complexes I, COX, $\alpha \mathrm{KGDH}$, and ATP synthase activities

Reduction of ROS production and mtDNA oxidative damage

Restoration of mitochondrial antioxidant enzymes and

OGG1 activities

Suppression of OGG1 and MnSOD acetylation

Modulation of mitochondrial dynamics proteins (Mfn1 and Drp1)

\section{Experimental AD models}

In vitro primary neurons from Tg2576 mice

In vitro $\mathrm{A} \beta_{22-35}$ peptide-treated

or APPswe and APPInd-overexpressed N2a cell line

In vivo Tg2576 mice

In vivo MCAT/APP mice

In vitro $\mathrm{A} \beta$ peptide-treated $\mathrm{PC} 12$ cell line

In vivo APP/PSEN1 mice

In vivo APP/PSEN1 mice

In vitro $A \beta$ peptide-treated rat hippocampal neurons

In vitro OA-treated HT22 hippocampal

neurons

In vivo aluminum-treated rats

In vitro Tet-On A $442-G F P-o v e r e x p r e s s e d$

SH-SY5Y cell line

In vivo $3 \times T g-A D$ mice

Isolated mitochondria from hippocampus, cortex, and striatum of APP/PSEN1 mice

In vitro APP695-overexpressed N2a cell line

In vitro APPmut-overexpressed

neuroblastoma cell line

In vivo streptozotocin-infused Wistar rats

In vitro $\mathrm{A} \beta_{22-35}$ peptide-treated $\mathrm{SH}-\mathrm{SY} 5 \mathrm{Y}$ cell line

In vitro glutamate-treated PC12 cell line

In vivo APP751SL mice

In vivo APP/PSEN1 mice

In vivo aluminum-treated rats

In vivo P301L mice

In vivo TgCRND8 mice

In vivo APP/PSEN1 mice

In vitro copper-treated SH-SY5Y cell line

In vivo 3xTg-AD mice

Isolated mitochondria from APP/PSEN1 mice In vivo swimming-trained pregnant rats In vivo 3xTg-AD mice
(Mao et al., 2012)

\section{References}

(Manczak et al., 2010; Calkins et al., 2011; Reddy et al., 2017, Reddy et al., 2018)

(Jang and Surh, 2003; Porquet et al., 2014; Deng and Mi,

2016; Wang et al., 2018)

(Wang et al., 2014; Jiang et al., 2016; Sharma et al., 2016;

Godoy et al., 2017)

(Huang et al., 2017)

(Dragicevic et al., 2011b; Biasibetti et al., 2013; Zhang et al., 2017)

(Sood et al., 2011; Chang et al., 2014; Hagl et al., 2014; Gerenu et al., 2015; Reddy et al., 2016)

(Delic et al., 2015)

(Grossi et al., 2013; Pantano

et al., 2017)

(Peng et al., 2016; Omar et al. 2017)

(Pawlosky et al., 2017)

(Bo et al., 2014; Klein et al., 2019) 
TABLE 1 | Continued

\begin{tabular}{|c|c|c|c|}
\hline Treatment & Effect on mitochondria & Experimental AD models & References \\
\hline 2-deoxyglucose & $\begin{array}{l}\text { Increase of } \alpha \mathrm{KGDH} \text { level } \\
\text { Reduction of mitochondrial APP and A } \beta \text { oligomer level, } \\
\text { mitochondrial stress response proteins levels, } \mathrm{mt} \Delta \Psi\end{array}$ & $\begin{array}{l}\text { In vivo } 3 \times \text { Tg-AD mice } \\
\text { In vivo } A \beta \text { peptides-treated adult rats }\end{array}$ & $\begin{array}{l}\text { (Guo and Mattson, 2000; Yao } \\
\text { et al., 2011) }\end{array}$ \\
\hline Rapamycin & $\begin{array}{l}\text { Prevention of decrease of } \mathrm{mt} \Delta \Psi \\
\text { Stimulation of mitophagy/autophagy }\end{array}$ & In vitro $A \beta_{1-42}$ peptide-treated PC12 cell line & (Xue et al., 2016) \\
\hline $\begin{array}{l}\text { Spermidine, } \\
\text { Urolithin A, } \\
\text { Actinonin }\end{array}$ & Stimulation of mitophagy/autophagy & $\begin{array}{l}\text { In vivo } A \beta \text { and tau Caenorhabditis elegans } \\
\text { models } \\
\text { In vivo APP/PSEN1 mice }\end{array}$ & (Fang et al., 2019) \\
\hline
\end{tabular}

\section{Other mitochondrial-based therapy \\ Nicotinamide Prevention of OCR deficits \\ adenine Promotion of PGC-1 $\alpha$ level \\ dinucleotide (NAD) Restoration of $\mathrm{NAD}^{+}$and ATP level \\ Changes of mitochondrial dynamics fusion-fission \\ Block of ROS accumulation \\ Stimulation of mitophagy/autophagy}

In vitro APP/PSEN1-overexpressed

hippocampal neuroblastoma

In vitro $\mathrm{NMN}$-treated organotypic

hippocampal slice cultures (OHCs)

In vivo APP/PSEN1 mice

In vivo $A \beta$ oligomer-infused rats

In vivo Tg2576 mice

In vivo $A \beta$ and tau Caenorhabditis elegans

models

Isolated mitochondria from APP/PSEN1 mice In vitro APP695-overexpressed $\mathrm{CHO}$ cell line Isolated mitochondria from rat

In vitro mouse cortical neurons and SH-SY5Y In vitro APPswe-overexpressed HEK293 cell line

In vitro glutamate-treated CGNs
(Long et al., 2015; Wang et al., 2016; Fang et al., 2019)

(Chang et al., 2015, Chang et al., 2019)

(Zhang et al., 2010; Naga and Geddes, 2011; Eckert et al., 2012; Weisová et al., 2013) proteins levels, mitochondrial dynamics and morphology Attenuation of $\mathrm{Ca}^{2+}$ induced mitochondrial swelling proteins levels

AD, Alzheimer's disease; ETC, electron transport chain; RCC, respiratory chain complexes, mt $\triangle \Psi$ : mitochondrial membrane potential; OCR, oxygen consumption rates; ATP, adenosine triphosphate; MPTP, mitochondrial permeability transition pore; mtDNA, mitochondrial deoxyribonucleic acid; nuDNA, nuclear deoxyribonucleic acid; APE1, apurinic/ apyrimidinic endonuclease 1; MnSOD, manganese superoxide dismutase; OGG1, oxoguanine DNA glycosylase-1; $\alpha$ KGDH, $\alpha$-ketoglutarate dehydrogenase; COX, cytochrome $c$ oxidase or complex IV; TIM, translocase inner membrane; TOM, translocase outer membrane; Mfn1, mitofusin-1; Drp1, dynamin-1-like protein; PGC-1 $\alpha$, peroxisome-proliferatoractivated receptor $\gamma$ coactivator-1 $\alpha$; NAD, nicotinamide adenine dinucleotide; NADH, reduced nicotinamide adenine dinucleotide; ROS, reactive oxygen species; RNS, reactive nitrogen species; GSH, glutathione; GSSG, oxidized glutathione; 3-NT, 3-nitrotyrosine; MDA, malondiaaldehyde; SelM, selenoprotein M; 6-OHDA, 6-hydroxydopamine; OA, okadaic acid; $\mathrm{H}_{2} \mathrm{O}_{2}$, hydrogen peroxide; NMN, nicotinamide mononucleotide; $A \beta, \beta$-amyloid peptide; A $\beta P P$, $\beta$-amyloid precursor protein; PS1, presenilin 1; BACE1, $\beta$-secretase-1; HEK293, human embryonic kidney 293 cell lines; HUVEC, human umbilical vein endothelial cell line; M17, human neuroblastoma cell line; N2a, mouse neuroblastoma cell line; LUHMES, Lund human mesencephalic cell line; SH-SY5Y, human neuroblastoma cell lines; IMR-32, human neuroblastoma cell lines; PC12, pheochromocytoma of rat adrenal medulla-derived cell lines; OHCs, organotypic hippocampal slice cultures; NARP, cybrid cell lines bearing mtDNA mutation T8993G; CGN, cerebellar granule neurons; $5 x F A D$, mice expressing human APP and PSEN1 genes with a total of five AD-linked mutations, the Swedish, Florida, and London mutations in APP, and the M146L and L286V mutations in PSEN1; APP/PSEN1, mice contain human APP gene bearing the Swedish mutation and PS1 gene containing L166P mutation; TgP301S, mice expressing mutant human microtubule-associated protein tau (MAPT); Tg19959, mice expressing human APP gene bearing the Swedish mutation and Indiana mutation; TgCRND8, mice expressing human APP695 gene with the Swedish mutation and Indiana mutation; 3xTg-AD, mice contain three mutations (Swedish, MAPT, PS1) associated with familial AD; Tg2676 mice, mice expressing mutant human form of APP (isoform 695) with Swedish mutation; APP751SL, mice expressing the human APP bearing both Swedish and the London mutation; ApoE4 Tg mice, mice expressing human apolipoprotein E (APOE) gene; OXYS rats, senescence-accelerated rats; MCAT, mitochondria-targeted catalase; C. elegans, Caenorhabditis elegans.

Targeting directly the mitochondria with antioxidant compounds was always one of the most considered therapeutic strategies in $\mathrm{AD}$. In this regard, an antioxidant directed to mitochondria that has been tried was the coenzyme Q10 (CoQ10). CoQ10 has a quinone structure and is a component of the mitochondrial RCC. In a rat model for AD, CoQ10 prevented the cognitive decline (Dehghani Dolatabadi et al., 2012). Still, due to a low bioavailability in the brain (Kwong et al., 2002), CoQ10 has never been successful in humans. To overcome this issue, the mitoquinone mesylate (MitoQ) was optimized. MitoQ is an antioxidant compound made of ubiquinone conjugate with triphenylphosphonium (TPP). The TPP is necessary to target the molecule to the mitochondria because it helps to cross the lipid bilayers accumulating on the negative site of mitochondrial membranes (Kelso et al., 2001; Smith et al., 2003). MitoQ behaved as ROS scavenger and was tested in different $\mathrm{AD}$ model systems (see Table 1). Here, MitoQ shown to prevent oxidative damage, to protect RCC activity, to reduce $\mathrm{A} \beta$ peptide levels, synaptic loss, and astrogliosis, and to improve cognitive functions (McManus et al., 2011; Ng et al., 2014). As reported in the review from Ortiz (Perez Ortiz and Swerdlow, 2019), at the moment, MitoQ is tested in a small clinical trial to check its effect on cerebrovascular blood flow in AD. Similarly to MitoQ, other antioxidant compounds (SkQ1, MitoApo, astaxanthin) affect positively the mitochondrial functions (see Table 1) and could be potentially used to treat AD (Lobos et al., 2016; Stefanova et al., 2016; Brenza et al., 2017).

Another group of antioxidant molecules such as melatonin, a-lipoic acid (LA), N-Acetyl-cysteine (NAC), and Ginkgo biloba were tested in vivo and in vitro and showed protective effects on $\mathrm{A} \beta$ peptide accumulation and mitochondrial toxicity as well as on cognitive functions (Dong et al., 2010; Rosales-Corral et al., 2012a). Melatonin is a neurohormone produced by the pineal gland with neuroprotective functions in AD pathogenesis (Shukla et al., 2017). Melatonin is a ROS scavanger and showed some anti-amyloidogenic 
properties (Dong et al., 2010; Rosales-Corral et al., 2012a). At mitochondrial level, melatonin prevented the ROS production, the cardiolipin oxidation, and the mPTP opening, restored the $\mathrm{Ca}^{2+}$ balance, and reduced the caspase- 3 and -9 levels (Feng and Zhang, 2004; Jou et al., 2004; Petrosillo et al., 2009; Espino et al., 2010). Treatments with $\boldsymbol{\alpha}$-lipoic acid, a cofactor for many RCC enzymes, exhibited a positive effect on cognitive functions in clinical trials on $\mathrm{AD}$ patients and in murine models of aging and $\mathrm{AD}, \alpha$-lipoic acid affected also the formation and the stabilization of $A \beta$ peptide fibril as well as the protection against the $A \beta$ peptide toxicity in cultured hippocampal neurons (Liu et al., 2002; Lovell et al., 2003; Ono et al., 2006; Hager et al., 2007; Quinn et al., 2007; Sancheti et al., 2013). $\mathbf{N}$-Acetyl-cysteine (NAC) is the precursor of the endogenous antioxidant glutathione (GSH), a key molecule for the maintenance of mitochondrial functions (Traber et al., 1992). In vitro and in vivo, NAC had beneficial effects on $\mathrm{A} \beta$ peptide and phosphorylated tau levels with improvement of cognitive functions, protection against memory decline, and reduction of oxidative stress markers (see also Table 1) (Studer et al., 2001; Fu et al., 2006; Huang et al., 2010; Costa et al., 2016). In two clinical trials, subjects with MCI, AD, or early memory loss were treated for a long time with a nutraceutical formulation that also included NAC. Improvement of cognitive and behavioral functions was observed (Remington et al., 2015; Remington et al., 2016). G. biloba is a natural antioxidant already used in the Chinese traditional medicine. Table 1 shows all the effects of G. biloba on mitochondrial functions. Two clinical trials were performed to test the effect of G. biloba in the prevention against memory and cognitive decline in older adults and $\mathrm{AD}$ subjects. Unfortunately, no positive effects were observed in these tests (Snitz et al., 2009; Vellas et al., 2012).

The Szeto-Schiller (SS) tetrapeptides are a group of small peptides that due to their structure act as antioxidants and can reach the mitochondrial matrix and the IMM (Szeto, 2006). In one of $A D$ murine models, the $\mathbf{S S 3 1}$ reduced $A \beta$ peptide production, mitochondrial dysfunction, and enhanced mitochondrial biogenesis and synaptic activity (Calkins et al., 2011; Reddy et al., 2017). Recently, a combination of SS31 and the mitochondrial division inhibitor 1 (Mdivil) was tested in cultured AD cells with positive effects, suggesting that a combined treatment of mitochondria-targeted antioxidants could have higher effectiveness (Reddy et al., 2018).

An interesting preclinical study proposed to target the antioxidant enzyme catalase to the mitochondria. Catalase catalyzes the decomposition of hydrogen peroxide $\left(\mathrm{H}_{2} \mathrm{O}_{2}\right)$ in water $\left(\mathrm{H}_{2} \mathrm{O}\right)$ and oxygen $\left(\mathrm{O}_{2}\right)$ and is typically localized in the peroxisome. A double transgenic mouse with mitochondriatargeted catalase (MCAT) and APP was created, and the protective effects against abnormal APP processing, A $\beta$ peptide pathology, and lifespan extension were tested. Mitochondrial catalase showed beneficial outcomes in this highly artificial model. Although most of the antioxidant clinical trials were not entirely successful, this study proved that a direct target of an antioxidant to the mitochondria might still have a chance as a therapeutic approach in AD (Mao et al., 2012).

Despite the oxidative stress unbalance is an evident hallmark in $\mathrm{AD}$ and some mitochondrial-targeted antioxidant strategies showed promising effect on cognitive functions, none entered so far in the market as a valid $\mathrm{AD}$ treatment. There are different reasons to justify the failures (summarized in Persson et al. paper; Persson et al., 2014). The antioxidants at certain concentrations and conditions could behave as pro-oxidants and therefore they are more harmful than useful. The antioxidant administration during the clinical trials was probably started too late during the development of the disease suggesting that an early intervention could be more effective. Last, the antioxidant bioavailability in the brain could be low due to the difficulty of these molecules to cross the blood-brain barrier $(\mathrm{BBB})$ requiring a rational modification of their structure to overpass this issue.

\section{Phenylpropanoids}

The phenylpropanoids are natural compounds that exert many physiological functions crucial for the survival of plants. In this heterogeneous group of substances, many subclasses have been identified such as stilbenoids, flavonoids, curcuminoids, phenolate esters, and lignans. These compounds showed an effect against the $\mathrm{A} \beta$ peptide and tau pathologies, on the activation of the inflammation response, on the oxidative stress, and also on the mitochondrial dysfunction (Kolaj et al., 2018). Between others, resveratrol, quercetin, wogonin, epigallocatechin-3-gallate (EGCG), and curcumin were already tested and showed to promote mitochondrial biogenesis, to impede apoptotic pathways through inhibition of DNA fragmentation, ROS formation, and caspase-3 activation, and to reduce perturbation of $m t \Delta \Psi$ and ATP levels (see also Table 1 for the effects of phenylpropanoids on mitochondria in AD models) (Lagouge et al., 2006; Davis et al., 2009; Im et al., 2012; Valenti et al., 2013; Reddy et al., 2016). Furthermore, these compounds were able to restore the mitochondrial functions in a transgenic mouse model of AD (Dragicevic et al., 2011b). In particular in an in vitro study, EGCG, a major flavonoid component of the green tea, accumulated in mitochondria and exerted a strong influence on the mitochondrial functions proposing it as pharmacological treatment in AD (Schroeder et al., 2009; Dragicevic et al., 2011b). However, phenylpropanoids have a dual effect on mitochondrial function, depending on the concentration. For example, EGCG could increase apoptosis in cultured neurons at specific concentrations, while quercetin protected cultured hippocampal cells against $\mathrm{A} \beta$ peptide-induced apoptosis only in low concentrations (Chung et al., 2007; Ansari et al., 2009). Curcumin is an antioxidant compound with massive potential for the prevention and treatment of $\mathrm{AD}$. It showed beneficial effects on Tg2576 AD model mice, such as reduction of the brain oxidative stress and the neuroinflammation, but no effect in $\mathrm{AD}$ patients, probably due to a low bioavailability (Lim et al., 2001; Baum et al., 2008; Ringman et al., 2012). New strategies have been implemented to overpass this limitation and improve the curcumin pharmacokinetics, such as the nanotechnology-based delivery system, new pharmaceutical formulations, and the change in the way of administration (Reddy et al., 2014; Serafini et al., 2017).

Like the antioxidant, the use of the phenylpropanoids in $\mathrm{AD}$ treatment needs to be considered with caution and none of them has become a real therapy yet. The new AD clinical trials based on this group of molecules definitely require a broad design, a substantial revision, and a careful implementation. 


\section{Action on the Lifestyle Calories Restriction, Diet, Exercises}

Lifestyle activities, in particular exercise and diet, have been known to act at the mitochondrial level and should therefore be considered as possible interventions to treat AD. Table 1 reports the effects of the compounds and activities strictly related to the lifestyle on mitochondria from $\mathrm{AD}$ models.

A Mediterranean diet has been correlated to the reduction of the incidence of AD (Scarmeas et al., 2006; Karstens et al., 2019). The Mediterranean diet is mainly composed of fruits, vegetables, and omega-3 fatty acids, which are enriched in olive oil. It was observed that, for example, polyphenol-rich extra-virgin oil reduced mitochondria-generated oxidative stress and insulin resistance in high-fat diet fed rats (Lama et al., 2017). Another polyphenol component of olive oil called oleuropein aglycone (OLE) promoted autophagy, decreased aggregated proteins levels, and reduced the cognitive impairment in $\mathrm{AD}$ patients' brain (Grossi et al., 2013; Cordero et al., 2018). Hydroxytyrosol (HT), another bioactive compound of olive oil, ameliorated mitochondrial dysfunction in an animal model of AD (Peng et al., 2016). On the other side, higher consumption of fructose affected negatively the mitochondrial function in hippocampus from adult rats, suggesting that fructose consumption should be actively avoided (Cigliano et al., 2018). Ketones are another source of energy for the brain when there is a limited amount of available glucose (Owen et al., 1967). The ketone ester diet in a model of $\mathrm{AD}(3 \mathrm{xTgAD})$ had positive effects also on mitochondrial functions (Pawlosky et al., 2017). The therapeutic ketosis was suggested to reduce the $\mathrm{AD}$ brain pathology including the accumulation of $A \beta$ plaques and NFT (Kashiwaya et al., 2013). Of course, the results obtained in AD murine models have to be proven in humans through clinical trials (Puchowicz and Seyfried, 2017). In this regard, there are experiments going on at the University of Kansas about the effect of a ketogenic diet (KD) on participants with $\mathrm{AD}$, but no definitive results are available yet (Taylor et al., 2018; Taylor et al., 2019).

An extreme form of diet is represented by calorie restriction (CR). CR is a strong limitation on calorie intake without facing a lack of nutrients. It is well known that CR is an excellent way to extend lifespan, to increase insulin sensitivity, and to prevent agerelated diseases (Mattison et al., 2017). At the mitochondrial level, CR showed positive effects by affecting mitochondrial biogenesis through the induction of NO synthetase (eNOS) (Nisoli et al., 2005). Newly synthesized mitochondria led to an increase of mitophagy, reduction of ROS, increased ATP levels, and overall improvement of the mitochondrial quality and cell bioenergetics (López-Lluch et al., 2006). Furthermore, CR affected the mtDNA content as well as the amount of TFAM-bound mtDNA in rats (Picca et al., 2013). There are ongoing clinical studies around the world concerning the effect of $\mathrm{CR}$ and dietary intervention on MCI (Wilkins and Morris, 2017).

Physical exercise (PE) has been demonstrated to generally benefit the health of the body and mind, affecting properties such as brain plasticity and cognitive function. Hence, it could be a good prevention for age-related diseases (Hernández et al., 2015; Paillard et al., 2015). It is well known that PE targets mitochondria and improved mitochondrial function (see Table 1 to check the effects of PE on mitochondria in AD models). A study showed that PE increased mtDNA repair, ameliorated mitochondria respiratory function through the increase of RCC activity, attenuated ROS generation capacity together with a reduction of $A \beta_{1-42}$ peptide levels, and correlated with an amelioration of cognitive function in the hippocampus from the APP/PS1 transgenic mouse model of AD (Bo et al., 2014). However, data obtained in another AD mouse model (3xTg-AD) demonstrated that short-term exercise did not augment the critical gene expression of mitochondrial biogenesis, even if the glucose metabolism was overall improved (Do et al., 2018). Maternal exercise during pregnancy resulted in a positive effect on mitochondrial function concerning the onset of $\mathrm{AD}$. In this study, a protective effect against $A \beta$ oligomer-induced neurotoxicity in the adult offspring brain rats was shown (Klein et al., 2019). Clinical trials with PE were performed in older adults with healthy as well as impaired cognitive function. $\mathrm{A} \beta_{1-42}$ concentration in plasma and CSF was modified. In the brain, improvements of cognitive and executive functions, and even a change of hippocampal volume and memory, were observed, together with a reduced brain atrophy (Baker et al., 2010; Erickson et al., 2011; Vidoni et al., 2015; Yokoyama et al., 2015). Of course, in these human studies, neither a direct effect of PE on mitochondria nor the molecular mechanisms of PE benefits have been proved. However, all the studies performed in animal models positively supported the hypothesis that PE may have a beneficial effect on mitochondrial functions and glucose metabolism also in humans.

Diet, CR, and PE can also be combined to improve the quality of human aging and to prevent neurodegenerative disease (Rege et al., 2017). These approaches were shown to affect mitophagy, the cellular removal mechanism for damaged mitochondria, indicating the mitophagy as a new and promising therapeutic target to prevent the progression of the diseases. Experimental evidences from rodent studies showed that fasting and exercises could have a beneficial effect not only on mitophagy but also on mitochondrial biogenesis, reduction of oxidative stress, and overall neuronal plasticity (Alirezaei et al., 2010). Other strategies to boost mitophagy in order to delay $\mathrm{AD}$ are the use of compounds like 2-deoxyglucose, which protects neurons and enhances mitochondrial functions (Table 1) (Duan and Mattson, 1999; Yao et al., 2011). Additional molecules that promote autophagy/mitophagy are rapamycin, spermidine, urolithins, and the antibiotic actinonin (Spilman et al., 2010; Morselli et al., 2011; Ryu et al., 2016; Fang et al., 2019). The mTOR inhibitor rapamycin was already demonstrated to have beneficial effects on a mouse AD model (Spilman et al., 2010). Testing these molecules in clinical AD might be worth it.

\section{Other Mitochondria-Based AD Therapy Oxaloacetate}

Treatment with oxaloacetate (OOA), an intermediate of the Krebs cycle and gluconeogenesis, has been proposed as a new therapeutic approach for $\mathrm{AD}$, and it was already tested in some AD subjects (Swerdlow et al., 2016). Studies 
involving OOA performed in mice showed positive effects on glycolysis, respiratory fluxes, mtDNA and mtDNA-encoded proteins, activation of mitochondrial biogenesis, hippocampal neurogenesis activity, neuroinflammation, and change in brain insulin signaling (Wilkins et al., 2014). Despite there are no studies about the direct efficacy of OOA treatment on mitochondria in $\mathrm{AD}$ models, clinical trials with $\mathrm{OOA}$ in $\mathrm{AD}$ are ongoing.

\section{NAD}

Nicotinamide adenine dinucleotide (NAD) is an intermediate common to several mitochondrial metabolic pathways such as glycolysis, TCA cycle, and oxidative phosphorylation. Studies on in vitro and in vivo AD models proved that NAD treatments acted directly on mitochondrial functions and were beneficial (Table 1). In the past, the effect of a stabilized oral NAD formulation on cognitive functions in $\mathrm{AD}$ patients was also tested. The rationale behind this testing was based on the enhancement of the cellular bioenergetic to improve brain performance in the fight against neurodegenerative diseases. Interestingly, after 6 months of treatment, the subjects with probable $\mathrm{AD}$ showed no cognitive deterioration suggesting that NAD could be an excellent method to prevent the AD progression (Demarin et al., 2004). However, further studies are needed to prove NAD as an effective treatment to slow down $\mathrm{AD}$.

\section{Pioglitazone}

The pioglitazone is a peroxisome proliferator-activated receptor gamma (PPAR $\gamma)$ agonist. PPAR $\gamma$ is a ligand-activated nuclear transcription factor that has a role in regional transcriptional regulation of chr19q13.32 (Subramanian et al., 2017). This region contains the TOMM40-APOE-APOC1 genes and, as already mentioned, TOMM40 and APOE4 genes are risk factors for the LOAD development. Pioglitazone was able to decrease the transcription of TOMM40, APOE, and APOC1 genes making this molecule an interesting candidate in the $\mathrm{AD}$ therapy (Subramanian et al., 2017). In CHO cell line overexpressing APP695 isoform, pioglitazone lowered the $A \beta_{1-42}$ level and restored the mitochondrial activity (Chang et al., 2015). These results were then confirmed in vivo in APP/PSEN1 mice (Table 1) (Chang et al., 2019).

Pioglitazone is usually used to treat diabetes mellitus type 2 . Some years ago, the pharmaceutical company Takeda used this compound in a large and global Alzheimer's prevention study called TOMMORROW to slow down the progression from $\mathrm{MCI}$ to $\mathrm{AD}$. The people involved were selected based on their $A P O E$ and TOMM40 genotype without considering $A \beta$ status. In 2018, phase III of this prevention trial, unfortunately, closed down because the results against symptomatic $\mathrm{AD}$ were negative, despite some improvement in brain metabolism.

\section{Dimebon}

Another compound that affects mitochondria but failed the AD clinical trial was dimebon (latrepirdine). Dimebon (latrepirdine) is an old antihistaminic drug (first generation of
$\mathrm{H} 1$-antagonist) used against allergies that was selected in an $\mathrm{AD}$ clinical trial because it demonstrated cognition and memoryenhancing properties in rats treated with neurotoxin (Bachurin et al., 2001). Moreover, dimebon showed a substantial effect on mitochondria from different AD models (Table 1). Anyway, dimebon lacked reproducibility in the $\mathrm{AD}$ clinical trials and showed opposite effects on neuropsychiatric and cognitive symptoms, and daily activities (Bachurin et al., 2001; Doody et al., 2008). In a review from 2018, Eckert et al. asked the scientific community to reevaluate the drug dimebon as a potential treatment of $\mathrm{AD}$ since one of the clinical trials was able to show a slight improvement of mitochondrial functions after using dimebon in respect of the substantial effect on cognition and behavior (Eckert et al., 2018).

\section{CONCLUSION}

In a multitude of studies, mitochondrial dysfunction has been demonstrated to be a crucial feature of AD. Several experimental results suggested that a decline of mitochondrial activity happens during aging and may get worse at early stages of the disease, contributing to disease onset. However, more thorough investigations are needed to properly address this point. The suitability of the mitochondria as a target in $\mathrm{AD}$ treatment is still under discussion, considering that some pharmacological trials were not successful and others were more promising, but none led to a real marketable AD drug. Nevertheless, the current understanding of $\mathrm{AD}$ indicates that a complete cure may not be reachable yet. Future research efforts should be invested to i) understand the real chronology of events, ii) collocate correctly the mitochondrial dysfunction inside this temporal sequence, and iii) establish if the mitochondrial dysfunctions are a primary cause or a secondary event. Only when these three key points will be correctly settled, it will be easier to intervene pharmacologically and no more time and money will be wasted for futile therapeutic studies. The failures of the respective drugs or clinical trials often happened because the underlying scientific background was not always very robust or because the models and the tools used to prove the basal hypothesis were not always well defined or validated. Therefore, a more rational approach to a complex human disease like $\mathrm{AD}$ is needed as well as an improvement of communication between the different scientific disciplines in order to achieve a better understanding of the disease etiology and to develop new and more effective drugs.

\section{AUTHOR CONTRIBUTIONS}

GC conceived the idea and prepared the manuscript. WV reviewed the draft and provided important information for the completion of this manuscript.

\section{FUNDING}

The Deutsche Forschungsgemeinschaft (Grant No VO 657/5-2 to WV) supported the work in our laboratory. 


\section{REFERENCES}

Ajith, T. A., Nima, N., Veena, R. K., Janardhanan, K. K., and Antonawich, F. (2014). Effect of palladium $\alpha$-lipoic acid complex on energy in the brain mitochondria of aged rats. Altern. Ther. Health Med. 20, 27-35.

Alirezaei, M., Kemball, C. C., Flynn, C. T., Wood, M. R., Whitton, J. L., and Kiosses, W. B. (2010). Short-term fasting induces profound neuronal autophagy. Autophagy 6, 702-710. doi: 10.4161/auto.6.6.12376

Anandatheerthavarada, H. K., Biswas, G., Robin, M.-A., and Avadhani, N. G. (2003). Mitochondrial targeting and a novel transmembrane arrest of Alzheimer's amyloid precursor protein impairs mitochondrial function in neuronal cells. J. Cell. Biol. 161, 41-54. doi: 10.1083/jcb.200207030

Anandatheerthavarada, H. K., and Devi, L. (2007). Mitochondrial translocation of amyloid precursor protein and its cleaved products: relevance to mitochondrial dysfunction in Alzheimer's disease. Rev Neurosci. 18, 343-354. doi: 10.1515/ revneuro.2007.18.5.343

Ansari, M. A., Abdul, H. M., Joshi, G., Opii, W. O., and Butterfield, D. A. (2009). Protective effect of quercetin in primary neurons against Abeta(1-42): relevance to Alzheimer's disease. J. Nutr. Biochem. 20, 269-275. doi: 10.1016/j. jnutbio.2008.03.002

Area-Gomez, E., de Groof, A., Bonilla, E., Montesinos, J., Tanji, K., Boldogh, I., et al. (2018). A key role for MAM in mediating mitochondrial dysfunction in Alzheimer disease. Cell. Death Dis. 9, 335. doi: 10.1038/s41419-017-0215-0

Arlt, S., Müller-Thomsen, T., Beisiegel, U., and Kontush, A. (2012). Effect of oneyear vitamin C- and E-supplementation on cerebrospinal fluid oxidation parameters and clinical course in Alzheimer's disease. Neurochem. Res. 37, 2706-2714. doi: 10.1007/s11064-012-0860-8

Bachurin, S., Bukatina, E., Lermontova, N., Tkachenko, S., Afanasiev, A., Grigoriev, V., et al. (2001). Antihistamine agent Dimebon as a novel neuroprotector and a cognition enhancer. Ann. N. Y. Acad. Sci. 939, 425-435. doi: 10.1111/j.1749-6632.2001.tb03654.x

Baker, L. D., Frank, L. L., Foster-Schubert, K., Green, P. S., Wilkinson, C. W., McTiernan, A., et al. (2010). Aerobic exercise improves cognition for older adults with glucose intolerance, a risk factor for Alzheimer's disease. J. Alzheimers Dis. 22, 569-579. doi: 10.3233/JAD-2010-100768

Balaban, H., Nazıroğlu, M., Demirci, K., and Övey, İ. S. (2017). The protective role of selenium on scopolamine-induced memory impairment, oxidative stress, and apoptosis in aged rats: the involvement of TRPM2 and TRPV1 channels. Mol. Neurobiol. 54, 2852-2868. doi: 10.1007/s12035-016-9835-0

Baum, L., Lam, C. W. K., Cheung, S. K.-K., Kwok, T., Lui, V., Tsoh, J., et al. (2008). Six-month randomized, placebo-controlled, double-blind, pilot clinical trial of curcumin in patients with Alzheimer disease. J. Clin. Psychopharmacol. 28, 110-113. doi: 10.1097/jcp.0b013e318160862c

Beck, S. J., Guo, L., Phensy, A., Tian, J., Wang, L., Tandon, N., et al. (2016). Deregulation of mitochondrial F1FO-ATP synthase via OSCP in Alzheimer's disease. Nat. Commun. 7, 11483. doi: 10.1038/ncomms11483

Bernardi, P. (1999). Mitochondrial transport of cations: channels, exchangers, and permeability transition. Physiol. Rev. 79, 1127-1155. doi: 10.1152/ physrev.1999.79.4.1127

Biasibetti, R., Tramontina, A. C., Costa, A. P., Dutra, M. F., Quincozes-Santos, A., Nardin, P., et al. (2013). Green tea (-)epigallocatechin-3-gallate reverses oxidative stress and reduces acetylcholinesterase activity in a streptozotocininduced model of dementia. Behav. Brain Res. 236, 186-193. doi: 10.1016/j. bbr.2012.08.039

Billups, B., and Forsythe, I. D. (2002). Presynaptic mitochondrial calcium sequestration influences transmission at mammalian central synapses. J. Neurosci. 22, 5840-5847. doi: 10.1523/JNEUROSCI.22-14-05840.2002

Birnbaum, J. H., Wanner, D., Gietl, A. F., Saake, A., Kündig, T. M., Hock, C., et al. (2018). Oxidative stress and altered mitochondrial protein expression in the absence of amyloid- $\beta$ and tau pathology in iPSC-derived neurons from sporadic Alzheimer's disease patients. Stem Cell. Res. 27, 121-130. doi: 10.1016/j.scr.2018.01.019

Bo, H., Kang, W., Jiang, N., Wang, X., Zhang, Y., and Ji, L. L. (2014). Exerciseinduced neuroprotection of hippocampus in APP/PS1 transgenic mice via upregulation of mitochondrial 8-oxoguanine DNA glycosylase. Oxid. Med. Cell. Longev. 2014, 834502. doi: 10.1155/2014/834502

Boland, B., Kumar, A., Lee, S., Platt, F. M., Wegiel, J., Yu, W. H., et al. (2008). Autophagy induction and autophagosome clearance in neurons: relationship to autophagic pathology in Alzheimer's disease. J. Neurosci. 28, 6926-6937. doi: 10.1523/JNEUROSCI.0800-08.2008

Brenza, T. M., Ghaisas, S., Ramirez, J. E. V., Harischandra, D., Anantharam, V., Kalyanaraman, B., et al. (2017). Neuronal protection against oxidative insult by polyanhydride nanoparticle-based mitochondria-targeted antioxidant therapy. Nanomedicine 13, 809-820. doi: 10.1016/j.nano.2016.10.004

Butterfield, D. A., and Halliwell, B. (2019). Oxidative stress, dysfunctional glucose metabolism and Alzheimer disease. Nat. Rev. Neurosci. 20, 148-160. doi: 10.1038/s41583-019-0132-6

Butterfield, D. A., Poon, H. F., St Clair, D., Keller, J. N., Pierce, W. M., Klein, J. B., etal. (2006). Redox proteomics identification of oxidatively modified hippocampal proteins in mild cognitive impairment: insights into the development of Alzheimer's disease. Neurobiol. Dis. 22, 223-232. doi: 10.1016/j.nbd.2005.11.002

Cai, Q., and Tammineni, P. (2017). Mitochondrial aspects of synaptic dysfunction in Alzheimer's disease. J. Alzheimers Dis. 57, 1087-1103. doi: 10.3233/ JAD-160726

Calkins, M. J., and Reddy, P. H. (2011). Amyloid beta impairs mitochondrial anterograde transport and degenerates synapses in Alzheimer's disease neurons. Biochim. Biophys. Acta 1812, 507-513. doi: 10.1016/j.bbadis.2011.01.007

Calkins, M. J., Manczak, M., Mao, P., Shirendeb, U., and Reddy, P. H. (2011). Impaired mitochondrial biogenesis, defective axonal transport of mitochondria, abnormal mitochondrial dynamics and synaptic degeneration in a mouse model of Alzheimer's disease. Hum. Mol. Genet. 20, 4515-4529. doi: 10.1093/hmg/ddr381

Cardoso, S. M., Proença, M. T., Santos, S., Santana, I., and Oliveira, C. R. (2004). Cytochrome c oxidase is decreased in Alzheimer's disease platelets. Neurobiol. Aging 25, 105-110. doi: 10.1016/S0197-4580(03)00033-2

Cenini, G., Rüb, C., Bruderek, M., and Voos, W. (2016). Amyloid $\beta$-peptides interfere with mitochondrial preprotein import competence by a coaggregation process. Mol. Biol. Cell 27, 3257-3272. doi: 10.1091/mbc.E16-05-0313

Chacinska, A., Koehler, C. M., Milenkovic, D., Lithgow, T., and Pfanner, N. (2009). Importing mitochondrial proteins: machineries and mechanisms. Cell 138, 628-644. doi: 10.1016/j.cell.2009.08.005

Chang, C.-H., Chen, H.-X., Yü, G., Peng, C.-C., and Peng, R. Y. (2014). Curcuminprotected PC12 cells against glutamate-induced oxidative toxicity. Food Technol. Biotechnol. 52, 468-478. doi: 10.17113/ftb.52.04.14.3622

Chang, K. L., Pee, H. N., Tan, W. P., Dawe, G. S., Holmes, E., Nicholson, J. K., et al. (2015). Metabolic profiling of CHO-AßPP695 cells revealed mitochondrial dysfunction prior to amyloid- $\beta$ pathology and potential therapeutic effects of both PPAR $\gamma$ and PPAR $\alpha$ Agonisms for Alzheimer's disease. J. Alzheimers Dis. 44, 215-231. doi: 10.3233/JAD-140429

Chang, K. L., Wong, L. R., Pee, H. N., Yang, S., and Ho, P. C.-L. (2019). Reverting metabolic dysfunction in cortex and cerebellum of APP/PS1 mice, a model for Alzheimer's disease by pioglitazone, a peroxisome proliferator-activated receptor gamma (PPAR $\gamma$ ) agonist. Mol. Neurobiol. doi: 10.1007/s12035-019-1586-2

Chen, P., Wang, R.-R., Ma, X.-J., Liu, Q., and Ni, J.-Z. (2013). Different forms of selenoprotein $M$ differentially affect $A \beta$ aggregation and ROS generation. Int. J. Mol. Sci. 14, 4385-4399. doi: 10.3390/ijms14034385

Cho, D.-H., Nakamura, T., Fang, J., Cieplak, P., Godzik, A., Gu, Z., et al. (2009). S-Nitrosylation of Drp1 mediates $\beta$-amyloid-related mitochondrial fission and neuronal injury. Science 324, 102. doi: 10.1126/science.1171091

Chung, W.-G., Miranda, C. L., and Maier, C. S. (2007). Epigallocatechin gallate (EGCG) potentiates the cytotoxicity of rotenone in neuroblastoma SH-SY5Y cells. Brain Res. 1176, 133-142. doi: 10.1016/j.brainres.2007.07.083

Cigliano, L., Spagnuolo, M. S., Crescenzo, R., Cancelliere, R., Iannotta, L., Mazzoli, A., et al. (2018). Short-term fructose feeding induces inflammation and oxidative stress in the hippocampus of young and adult rats. Mol. Neurobiol. 55, 2869-2883. doi: 10.1007/s12035-017-0518-2

Cipak Gasparovic, A., Zarkovic, N., Zarkovic, K., Semen, K., Kaminskyy, D., Yelisyeyeva, O., et al. (2017). Biomarkers of oxidative and nitro-oxidative stress: conventional and novel approaches. Br. J. Pharmacol. 174, 1771-1783. doi: $10.1111 /$ bph. 13673

Cobley, J. N., Fiorello, M. L., and Bailey, D. M. (2018). 13 reasons why the brain is susceptible to oxidative stress. Redox Biol. 15, 490-503. doi: 10.1016/j. redox.2018.01.008

Coffey, E. E., Beckel, J. M., Laties, A. M., and Mitchell, C. H. (2014). Lysosomal alkalization and dysfunction in human fibroblasts with the Alzheimer's diseaselinked presenilin $1 \mathrm{~A} 246 \mathrm{E}$ mutation can be reversed with cAMP. Neuroscience 263, 111-124. doi: 10.1016/j.neuroscience.2014.01.001 
Cordero, J. G., García-Escudero, R., Avila, J., Gargini, R., and GarcíaEscudero, V. (2018). Benefit of oleuropein aglycone for Alzheimer's disease by promoting autophagy. Oxid. Med. Cell. Longev. 2018, 5010741. doi: $10.1155 / 2018 / 5010741$

Costa, M., Bernardi, J., Fiuza, T., Costa, L., Brandão, R., and Pereira, M. E. (2016). $\mathrm{N}$-acetylcysteine protects memory decline induced by streptozotocin in mice. Chem. Biol. Interact. 253, 10-17. doi: 10.1016/j.cbi.2016.04.026

Davies, G., Harris, S. E., Reynolds, C. A., Payton, A., Knight, H. M., Liewald, D.C., et al. (2014). A genome-wide association study implicates the APOE locus in nonpathological cognitive ageing. Mol. Psychiatry 19, 76-87. doi: 10.1038/ mp.2012.159

Davis, J. M., Murphy, E. A., Carmichael, M. D., and Davis, B. (2009). Quercetin increases brain and muscle mitochondrial biogenesis and exercise tolerance. Am. J. Physiol. Regul. Integr. Comp. Physiol. 296, R1071-R1077. doi: 10.1152/ ajpregu.90925.2008

de Brito, O. M., and Scorrano, L. (2008). Mitofusin 2 tethers endoplasmic reticulum to mitochondria. Nature 456, 605-610. doi: 10.1038/nature07534

De Stefani, D., Raffaello, A., Teardo, E., Szabò, I., and Rizzuto, R. (2011). A fortykilodalton protein of the inner membrane is the mitochondrial calcium uniporter. Nature 476, 336-340. doi: 10.1038/nature10230

Dehghani Dolatabadi, H. R., Reisi, P., Alaei, H., Azizi Malekabadi, H., and Pilehvarian, A. A. (2012). Folic acid and coenzyme Q10 ameliorate cognitive dysfunction in the rats with intracerebroventricular injection of streptozotocin. Iran J. Basic Med. Sci. 15, 719-724.

Delic, V., Brownlow, M., Joly-Amado, A., Zivkovic, S., Noble, K., Phan, T.-A., et al. (2015). Calorie restriction does not restore brain mitochondrial function in P301L tau mice, but it does decrease mitochondrial F0F1-ATPase activity. Mol. Cell. Neurosci. 67, 46-54. doi: 10.1016/j.mcn.2015.06.001

Demarin, V., Podobnik, S. S., Storga-Tomic, D., and Kay, G. (2004). Treatment of Alzheimer's disease with stabilized oral nicotinamide adenine dinucleotide: a randomized, double-blind study. Drugs Exp. Clin. Res. 30, 27-33.

Deng, H., and Mi, M.-T. (2016). Resveratrol attenuates A $\beta 25-35$ caused neurotoxicity by inducing autophagy through the TyrRS-PARP1SIRT1 signaling pathway. Neurochem. Res. 41, 2367-2379. doi: 10.1007/ s11064-016-1950-9

Devi, L., Prabhu, B. M., Galati, D. F., Avadhani, N. G., and Anandatheerthavarada, H. K. (2006). Accumulation of amyloid precursor protein in the mitochondrial import channels of human Alzheimer's disease brain is associated with mitochondrial dysfunction. J. Neurosci. 26, 9057-9068. doi: 10.1523/ JNEUROSCI.1469-06.2006

Dixit, S., Fessel, J. P., and Harrison, F. E. (2017). Mitochondrial dysfunction in the APP/PSEN1 mouse model of Alzheimer's disease and a novel protective role for ascorbate. Free Radic. Biol. Med. 112, 515-523. doi: 10.1016/j. freeradbiomed.2017.08.021

Do, K., Laing, B. T., Landry, T., Bunner, W., Mersaud, N., Matsubara, T., et al. (2018). The effects of exercise on hypothalamic neurodegeneration of Alzheimer's disease mouse model. PLoS ONE 13, e0190205. doi: 10.1371/ journal.pone.0190205

Dong, W., Huang, F., Fan, W., Cheng, S., Chen, Y., Zhang, W., et al. (2010). Differential effects of melatonin on amyloid-beta peptide 25-35-induced mitochondrial dysfunction in hippocampal neurons at different stages of culture. J. Pineal. Res. 48, 117-125. doi: 10.1111/j. 1600-079X.2009.00734.x

Doody, R. S., Gavrilova, S. I., Sano, M., Thomas, R. G., Aisen, P. S., Bachurin, S. O., et al. (2008). Effect of dimebon on cognition, activities of daily living, behaviour, and global function in patients with mild-to-moderate Alzheimer's disease: a randomised, double-blind, placebo-controlled study. Lancet 372, 207-215. doi: 10.1016/S0140-6736(08)61074-0

Dragicevic, N., Copes, N., O’Neal-Moffitt, G., Jin, J., Buzzeo, R., Mamcarz, M., et al. (2011a). Melatonin treatment restores mitochondrial function in Alzheimer's mice: a mitochondrial protective role of melatonin membrane receptor signaling. J. Pineal. Res. 51, 75-86. doi: 10.1111/j.1600-079X.2011.00864.x

Dragicevic, N., Delic, V., Cao, C., Copes, N., Lin, X., Mamcarz, M., et al. (2012). Caffeine increases mitochondrial function and blocks melatonin signaling to mitochondria in Alzheimer's mice and cells. Neuropharmacology 63, 13681379. doi: 10.1016/j.neuropharm.2012.08.018

Dragicevic, N., Smith, A., Lin, X., Yuan, F., Copes, N., Delic, V., et al. (2011b). Green tea epigallocatechin-3-gallate (EGCG) and other flavonoids reduce
Alzheimer's amyloid-induced mitochondrial dysfunction. J. Alzheimers Dis. 26, 507-521. doi: 10.3233/JAD-2011-101629

Du, H., Guo, L., Yan, S., Sosunov, A. A., McKhann, G. M., and Yan, S. S. (2010). Early deficits in synaptic mitochondria in an Alzheimer's disease mouse model. Proc. Natl. Acad. Sci. U.S.A. 107, 18670-18675. doi: 10.1073/pnas.1006586107

Duan, W., and Mattson, M. P. (1999). Dietary restriction and 2-deoxyglucose administration improve behavioral outcome and reduce degeneration of dopaminergic neurons in models of Parkinson's disease. J. Neurosci. Res. 57, 195206. doi: 10.1002/(SICI)1097-4547(19990715)57:2<195::AID-JNR5>3.0.CO;2-P

Dubey, M., Chaudhury, P., Kabiru, H., and Shea, T. B. (2008). Tau inhibits anterograde axonal transport and perturbs stability in growing axonal neurites in part by displacing kinesin cargo: neurofilaments attenuate taumediated neurite instability. Cell Motil. Cytoskeleton 65, 89-99. doi: 10.1002/ $\mathrm{cm} .20243$

DuBoff, B., Götz, J., and Feany, M. B. (2012). Tau promotes neurodegeneration via DRP1 mislocalization in vivo. Neuron 75, 618-632. doi: 10.1016/j. neuron.2012.06.026

Dumont, M., Kipiani, K., Yu, F., Wille, E., Katz, M., Calingasan, N. Y., et al. (2011). Coenzyme Q10 decreases amyloid pathology and improves behavior in a transgenic mouse model of Alzheimer's disease. J. Alzheimers Dis 27, 211-223. doi: 10.3233/JAD-2011-110209

Durán-Prado, M., Frontiñán, J., Santiago-Mora, R., Peinado, J. R., ParradoFernández, C., Gómez-Almagro, M. V., et al. (2014). Coenzyme Q10 protects human endothelial cells from $\beta$-amyloid uptake and oxidative stress-induced injury. PLoS ONE 9, e109223. doi: 10.1371/journal.pone.0109223

Eckert, A., Keil, U., Kressmann, S., Schindowski, K., Leutner, S., Leutz, S., et al. (2003). Effects of EGb 761 Ginkgo biloba extract on mitochondrial function and oxidative stress. Pharmacopsychiatry 36 Suppl 1, S15-S23. doi: 10.1055/s-2003-40449

Eckert, A., Keil, U., Scherping, I., Hauptmann, S., and Müller, W. E. (2005). Stabilization of mitochondrial membrane potential and improvement of neuronal energy metabolism by Ginkgo biloba extract EGb 761. Ann. N. Y. Acad. Sci. 1056, 474-485. doi: 10.1196/annals.1352.023

Eckert, A., Nisbet, R., Grimm, A., and Götz, J. (2014). March separate, strike together-Role of phosphorylated TAU in mitochondrial dysfunction in Alzheimer's disease. (BBA) - Mol. Basis Dis. 1842, 1258-1266. doi: 10.1016/j. bbadis.2013.08.013

Eckert, A., Schulz, K. L., Rhein, V., and Götz, J. (2010). Convergence of amyloid- $\beta$ and Tau pathologies on mitochondria in vivo. Mol. Neurobiol. 41, 107-114. doi: 10.1007/s12035-010-8109-5

Eckert, S. H., Eckmann, J., Renner, K., Eckert, G. P., Leuner, K., and Muller, W. E. (2012). Dimebon ameliorates amyloid- $\beta$ induced impairments of mitochondrial form and function. J. Alzheimers Dis. 31, 21-32. doi: 10.3233/JAD-2012-120310

Eckert, S. H., Gaca, J., Kolesova, N., Friedland, K., Eckert, G. P., and Muller, W. E. (2018). Mitochondrial pharmacology of dimebon (latrepirdine) calls for a new look at its possible therapeutic potential in Alzheimer's disease. Aging Dis. 9, 729-744. doi: 10.14336/AD.2017.1014

Elipenahli, C., Stack, C., Jainuddin, S., Gerges, M., Yang, L., Starkov, A., et al. (2012). Behavioral improvement after chronic administration of coenzyme Q10 in P301S transgenic mice. J. Alzheimers Dis. 28, 173-182. doi: 10.3233/ JAD-2011-111190

Erickson, K. I., Voss, M. W., Prakash, R. S., Basak, C., Szabo, A., Chaddock, L., et al. (2011). Exercise training increases size of hippocampus and improves memory. Proc. Natl. Acad. Sci. U.S.A. 108, 3017-3022. doi: 10.1073/ pnas. 1015950108

Espino, J., Bejarano, I., Redondo, P. C., Rosado, J. A., Barriga, C., Reiter, R. J., et al. (2010). Melatonin reduces apoptosis induced by calcium signaling in human leukocytes: evidence for the involvement of mitochondria and Bax activation. J. Membr. Biol. 233, 105-118. doi: 10.1007/s00232-010-9230-0

Fang, E. F., Hou, Y., Palikaras, K., Adriaanse, B. A., Kerr, J. S., Yang, B., et al. (2019). Mitophagy inhibits amyloid- $\beta$ and tau pathology and reverses cognitive deficits in models of Alzheimer's disease. Nat. Neurosci. 22, 401-412. doi: 10.1038/ s41593-018-0332-9

Feng, Z., and Zhang, J.-T. (2004). Protective effect of melatonin on beta-amyloidinduced apoptosis in rat astroglioma C6 cells and its mechanism. Free Radic. Biol. Med. 37, 1790-1801. doi: 10.1016/j.freeradbiomed.2004.08.023

Filadi, R., Greotti, E., Turacchio, G., Luini, A., Pozzan, T., and Pizzo, P. (2016). Presenilin 2 modulates endoplasmic reticulum-mitochondria coupling by 
tuning the antagonistic effect of mitofusin 2. Cell. Rep. 15, 2226-2238. doi: 10.1016/j.celrep.2016.05.013

Francis, P. T. (2005). The interplay of neurotransmitters in Alzheimer's disease. CNS Spectr. 10, 6-9. doi: 10.1017/S1092852900014164

Fu, A.-L., Dong, Z.-H., and Sun, M.-J. (2006). Protective effect of N-acetyl-Lcysteine on amyloid beta-peptide-induced learning and memory deficits in mice. Brain Res. 1109, 201-206. doi: 10.1016/j.brainres.2006.06.042

Galasko, D. R., Peskind, E., Clark, C. M., Quinn, J. F., Ringman, J. M., Jicha, G. A., et al. (2012). Antioxidants for Alzheimer disease: a randomized clinical trial with cerebrospinal fluid biomarker measures. Arch. Neurol. 69, 836-841. doi: 10.1001/archneurol.2012.85

Gan, X., Huang, S., Wu, L., Wang, Y., Hu, G., Li, G., et al. (2014). Inhibition of ERK-DLP1 signaling and mitochondrial division alleviates mitochondrial dysfunction in Alzheimer's disease cybrid cell. Biochim. Biophys. Acta 1842, 220-231. doi: 10.1016/j.bbadis.2013.11.009

García-Blanco, A., Baquero, M., Vento, M., Gil, E., Bataller, L., and CháferPericás, C. (2017). Potential oxidative stress biomarkers of mild cognitive impairment due to Alzheimer disease. J. Neurol. Sci. 373, 295-302. doi: 10.1016/j.jns.2017.01.020

Gazit, N., Vertkin, I., Shapira, I., Helm, M., Slomowitz, E., Sheiba, M., et al. (2016). IGF-1 Receptor differentially regulates spontaneous and evoked transmission via mitochondria at hippocampal synapses. Neuron 89, 583-597. doi: 10.1016/j. neuron.2015.12.034

Gerenu, G., Liu, K., Chojnacki, J. E., Saathoff, J. M., Martínez-Martín, P., Perry, G., et al. (2015). Curcumin/melatonin hybrid 5-(4-hydroxy-phenyl)-3-oxopentanoic acid [2-(5-methoxy-1H-indol-3-yl)-ethyl]-amide ameliorates AD-like pathology in the APP/PS1 mouse model. ACS Chem. Neurosci. 6, 1393-1399. doi: 10.1021/acschemneuro.5b00082

Gibson, G. E., and Shi, Q. (2010). A mitocentric view of Alzheimer's disease suggests multi-faceted treatments. J. Alzheimers Dis. 20 Suppl 2, S591-S607. doi: 10.3233/JAD-2010-100336

Glater, E. E., Megeath, L. J., Stowers, R. S., and Schwarz, T. L. (2006). Axonal transport of mitochondria requires milton to recruit kinesin heavy chain and is light chain independent. J. Cell Biol. 173, 545-557. doi: 10.1083/jcb.200601067

Godoy, J. A., Lindsay, C. B., Quintanilla, R. A., Carvajal, F. J., Cerpa, W., and Inestrosa, N. C. (2017). Quercetin exerts differential neuroprotective effects against $\mathrm{H}_{2} \mathrm{O}_{2}$ and $\mathrm{A} \beta$ aggregates in hippocampal neurons: the role of mitochondria. Mol. Neurobiol. 54, 7116-7128. doi: 10.1007/s12035-016-0203-x

Gottschalk, W. K., Lutz, M. W., He, Y. T., Saunders, A. M., Burns, D. K., Roses, A. D., et al. (2014). The broad impact of TOM40 on neurodegenerative diseases in aging. J. Parkinsons Dis Alzheimers Dis. 1, 1-25. doi: 10.13188/ 2376-922X.1000003

Green, D. R., and Kroemer, G. (2004). The pathophysiology of mitochondrial cell death. Science 305, 626-629. doi: 10.1126/science. 1099320

Grossi, C., Rigacci, S., Ambrosini, S., Ed Dami, T., Luccarini, I., Traini, C., et al. (2013). The polyphenol oleuropein aglycone protects TgCRND8 mice against $\mathrm{A} ß$ plaque pathology. PLoS ONE 8, e71702. doi: 10.1371/journal.pone.0071702

Guo, Z. H., and Mattson, M. P. (2000). In vivo 2-deoxyglucose administration preserves glucose and glutamate transport and mitochondrial function in cortical synaptic terminals after exposure to amyloid beta-peptide and iron: evidence for a stress response. Exp. Neurol. 166, 173-179. doi: 10.1006/ exnr.2000.7497

Hager, K., Kenklies, M., McAfoose, J., Engel, J., and Münch, G. (2007). Alpha-lipoic acid as a new treatment option for Alzheimer's disease-a 48 months follow-up analysis. J. Neural Transm. Suppl. 72, 189-193. doi: 10.1007/978-3-211-73574-9_24

Hagl, S., Heinrich, M., Kocher, A., Schiborr, C., Frank, J., and Eckert, G. P. (2014). Curcumin micelles improve mitochondrial function in a mouse model of Alzheimer's disease. J. Prev. Alzheimers Dis. 1, 80-83. doi: 10.14283/jpad.2014.2

Hansson Petersen, C. A., Alikhani, N., Behbahani, H., Wiehager, B., Pavlov, P. F., Alafuzoff, I., et al. (2008). The amyloid beta-peptide is imported into mitochondria via the TOM import machinery and localized to mitochondrial cristae. Proc. Natl. Acad. Sci. U.S.A. 105, 13145-13150. doi: 10.1073/ pnas. 0806192105

Hardy, J. A., and Higgins, G. A. (1992). Alzheimer's disease: the amyloid cascade hypothesis. Science 256, 184-185. doi: 10.1126/science.1566067

Hauptmann, S., Scherping, I., Dröse, S., Brandt, U., Schulz, K. L., Jendrach, M., et al. (2009). Mitochondrial dysfunction: an early event in Alzheimer pathology accumulates with age in AD transgenic mice. Neurobiol. Aging 30, 1574-1586. doi: 10.1016/j.neurobiolaging.2007.12.005

Hernández, S. S. S., Sandreschi, P. F., da Silva, F. C., Arancibia, B. A. V., da Silva, R., Gutierres, P. J. B., et al. (2015). What are the benefits of exercise for Alzheimer's disease? A systematic review of the past 10 years. J. Aging Phys. Act. 23, 659668. doi: 10.1123/japa.2014-0180

Hirai, K., Aliev, G., Nunomura, A., Fujioka, H., Russell, R. L., Atwood, C. S., et al. (2001). Mitochondrial abnormalities in Alzheimer's disease. J. Neurosci. 21, 3017-3023. doi: 10.1523/JNEUROSCI.21-09-03017.2001

Huang, D.-S., Yu, Y.-C., Wu, C.-H., and Lin, J.-Y. (2017). Protective effects of wogonin against Alzheimer's disease by inhibition of amyloidogenic pathway. Evid Based Complement Alternat. Med. 2017, 3545169. doi: 10.1155/2017/3545169

Huang, Q., Aluise, C. D., Joshi, G., Sultana, R., St Clair, D. K., Markesbery, W. R., et al. (2010). Potential in vivo amelioration by N-acetyl-L-cysteine of oxidative stress in brain in human double mutant APP/PS-1 knock-in mice: toward therapeutic modulation of mild cognitive impairment. J. Neurosci. Res. 88, 2618-2629. doi: $10.1002 /$ jnr.22422

Im, A.-R., Kim, Y.-H., Uddin, M. R., Lee, H. W., Chae, S. W., Kim, Y. H., et al. (2012). Scutellaria baicalensis extracts and flavonoids protect rat L6 cells from antimycin A-induced mitochondrial dysfunction. Evid Based Complement Alternat. Med. 2012, 517965. doi: 10.1155/2012/517965

Iturria-Medina, Y., Carbonell, F. M., Sotero, R. C., Chouinard-Decorte, F., Evans, A. C., and Alzheimer's Disease Neuroimaging Initiative (2017). Multifactorial causal model of brain (dis)organization and therapeutic intervention: application to Alzheimer's disease. Neuroimage 152, 60-77. doi: 10.1016/j. neuroimage.2017.02.058

Jang, J.-H., and Surh, Y.-J. (2003). Protective effect of resveratrol on beta-amyloidinduced oxidative PC12 cell death. Free Radic. Biol. Med. 34, 1100-1110. doi: 10.1016/S0891-5849(03)00062-5

Jiang, W., Luo, T., Li, S., Zhou, Y., Shen, X.-Y., He, F., et al. (2016). Quercetin protects against okadaic acid-induced injury via MAPK and PI3K/Akt/GSK3 $\beta$ signaling pathways in HT22 hippocampal neurons. PLoS ONE 11, e0152371. doi: 10.1371/journal.pone.0152371

Johnson, A. B., and Blum, N. R. (1970). Nucleoside phosphatase activities associated with the tangles and plaques of Alzheimer's disease: a histochemical study of natural and experimental neurofibrillary tangles. J. Neuropathol. Exp. Neurol. 29, 463-478. doi: 10.1097/00005072-197007000-00009

Johnson, S. C., La Rue, A., Hermann, B. P., Xu, G., Koscik, R. L., Jonaitis, E. M., et al. (2011). The effect of TOMM40 poly-T length on gray matter volume and cognition in middle-aged persons with APOE $\varepsilon 3 / \varepsilon 3$ genotype. Alzheimers Dement. 7, 456-465. doi: 10.1016/j.jalz.2010.11.012

Jou, M.-J., Peng, T.-I., Reiter, R. J., Jou, S.-B., Wu, H.-Y., and Wen, S.-T. (2004). Visualization of the antioxidative effects of melatonin at the mitochondrial level during oxidative stress-induced apoptosis of rat brain astrocytes. J. Pineal. Res. 37, 55-70. doi: 10.1111/j.1600-079X.2004.00140.x

Kang, I., Chu, C. T., and Kaufman, B. A. (2018). The mitochondrial transcription factor TFAM in neurodegeneration: emerging evidence and mechanisms. FEBS Lett. 592, 793-811. doi: 10.1002/1873-3468.12989

Kapogiannis, D., and Mattson, M. P. (2011). Disrupted energy metabolism and neuronal circuit dysfunction in cognitive impairment and Alzheimer's disease. Lancet Neurol. 10, 187-198. doi: 10.1016/S1474-4422(10)70277-5

Karran, E., Mercken, M., and De Strooper, B. (2011). The amyloid cascade hypothesis for Alzheimer's disease: an appraisal for the development of therapeutics. Nat. Rev. Drug Discov. 10, 698-712. doi: 10.1038/nrd3505

Karstens, A. J., Tussing-Humphreys, L., Zhan, L., Rajendran, N., Cohen, J., Dion, C., et al. (2019). Associations of the Mediterranean diet with cognitive and neuroimaging phenotypes of dementia in healthy older adults. Am. J. Clin. Nutr. 109, 361-368. doi: 10.1093/ajen/nqy275

Kashiwaya, Y., Bergman, C., Lee, J.-H., Wan, R., King, M. T., Mughal, M. R., et al. (2013). A ketone ester diet exhibits anxiolytic and cognition-sparing properties, and lessens amyloid and tau pathologies in a mouse model of Alzheimer's disease. Neurobiol. Aging 34, 1530-1539. doi: 10.1016/j. neurobiolaging.2012.11.023

Kaur, N., Dhiman, M., Perez-Polo, J. R., and Mantha, A. K. (2015). Ginkgolide $B$ revamps neuroprotective role of apurinic/apyrimidinic endonuclease 1 and mitochondrial oxidative phosphorylation against A $\beta 25-35$-induced neurotoxicity in human neuroblastoma cells. J. Neurosci. Res. 93, 938-947. doi: $10.1002 /$ jnr.23565 
Kelso, G. F., Porteous, C. M., Coulter, C. V., Hughes, G., Porteous, W. K., Ledgerwood, E. C., et al. (2001). Selective targeting of a redox-active ubiquinone to mitochondria within cells: antioxidant and antiapoptotic properties. J. Biol. Chem. 276, 4588-4596. doi: 10.1074/jbc.M009093200

Kim, S., Swaminathan, S., Shen, L., Risacher, S. L., Nho, K., Foroud, T., et al. (2011). Genome-wide association study of CSF biomarkers Abetal-42, t-tau, and p-tau181p in the ADNI cohort. Neurology 76, 69-79. doi: 10.1212/ WNL.0b013e318204a397

Kim, Y. J., Park, J. K., Kang, W. S., Kim, S. K., Han, C., Na, H. R., et al. (2017). Association between mitofusin 2 gene polymorphisms and late-onset Alzheimer's disease in the Korean population. Psychiatry Investig. 14, 81-85. doi: 10.4306/pi.2017.14.1.81

Klein, C. P., Hoppe, J. B., Saccomori, A. B., Dos Santos, B. G., Sagini, J. P., Crestani, M. S., et al. (2019). Physical exercise during pregnancy prevents cognitive impairment induced by amyloid- $\beta$ in adult offspring rats. Mol. Neurobiol. 56, 2022-2038. doi: 10.1007/s12035-018-1210-х

Kolaj, I., Imindu Liyanage, S., and Weaver, D. F. (2018). Phenylpropanoids and Alzheimer's disease: a potential therapeutic platform. Neurochem. Int. 120, 99-111. doi: 10.1016/j.neuint.2018.08.001

Kolosova, N. G., Tyumentsev, M. A., Muraleva, N. A., Kiseleva, E., Vitovtov, A. O., and Stefanova, N. A. (2017). Antioxidant SkQ1 alleviates signs of Alzheimer's disease-like pathology in old OXYS rats by reversing mitochondrial deterioration. Curr Alzheimer Res. 14, 1283-1292. doi: 10.2174/15672050146 66170621111033

Kook, S.-Y., Lee, K.-M., Kim, Y., Cha, M.-Y., Kang, S., Baik, S. H., et al. (2014). High-dose of vitamin $\mathrm{C}$ supplementation reduces amyloid plaque burden and ameliorates pathological changes in the brain of 5XFAD mice. Cell. Death Dis. 5, e1083. doi: 10.1038/cddis.2014.26

Krols, M., Bultynck, G., and Janssens, S. (2016). ER-mitochondria contact sites: a new regulator of cellular calcium flux comes into play. J. Cell. Biol. 214, 367370. doi: $10.1083 /$ jcb. 201607124

Kryscio, R. J., Abner, E. L., Caban-Holt, A., Lovell, M., Goodman, P., Darke, A. K., et al. (2017). Association of antioxidant supplement use and dementia in the prevention of Alzheimer's disease by vitamin $\mathrm{E}$ and selenium trial (PREADViSE). JAMA Neurol. 74, 567-573. doi: 10.1001/jamaneurol.2016.5778

Kwong, L. K., Kamzalov, S., Rebrin, I., Bayne, A.-C. V., Jana, C. K., Morris, P., et al. (2002). Effects of coenzyme $Q(10)$ administration on its tissue concentrations, mitochondrial oxidant generation, and oxidative stress in the rat. Free Radic. Biol. Med. 33, 627-638. doi: 10.1016/S0891-5849(02)00916-4

Lagouge, M., Argmann, C., Gerhart-Hines, Z., Meziane, H., Lerin, C., Daussin, F., et al. (2006). Resveratrol improves mitochondrial function and protects against metabolic disease by activating SIRT1 and PGC-1alpha. Cell 127, 1109-1122. doi: 10.1016/j.cell.2006.11.013

Lama, A., Pirozzi, C., Mollica, M. P., Trinchese, G., Di Guida, F., Cavaliere, G., et al. (2017). Polyphenol-rich virgin olive oil reduces insulin resistance and liver inflammation and improves mitochondrial dysfunction in high-fat diet fed rats. Mol. Nutr. Food Res. 61. doi: 10.1002/mnfr.201600418

Lee, J.-H., Yu, W. H., Kumar, A., Lee, S., Mohan, P. S., Peterhoff, C. M., et al. (2010). Lysosomal proteolysis and autophagy require presenilin 1 and are disrupted by Alzheimer-related PS1 mutations. Cell 141, 1146-1158. doi: 10.1016/j. cell.2010.05.008

Li, Z., Okamoto, K.-I., Hayashi, Y., and Sheng, M. (2004). The importance of dendritic mitochondria in the morphogenesis and plasticity of spines and synapses. Cell 119, 873-887. doi: 10.1016/j.cell.2004.11.003

Lim, G. P., Chu, T., Yang, F., Beech, W., Frautschy, S. A., and Cole, G. M. (2001). The curry spice curcumin reduces oxidative damage and amyloid pathology in an Alzheimer transgenic mouse. J. Neurosci. 21, 8370-8377. doi: 10.1523/ JNEUROSCI.21-21-08370.2001

Lin, M. T., Simon, D. K., Ahn, C. H., Kim, L. M., and Beal, M. F. (2002). High aggregate burden of somatic mtDNA point mutations in aging and Alzheimer's disease brain. Hum. Mol. Genet. 11, 133-145. doi: 10.1093/hmg/11.2.133

Linnertz, C., Anderson, L., Gottschalk, W., Crenshaw, D., Lutz, M. W., Allen, J., et al. (2014). The cis-regulatory effect of an Alzheimer's disease-associated poly- $T$ locus on expression of TOMM40 and apolipoprotein E genes. Alzheimers Dement. 10, 541-551. doi: 10.1016/j.jalz.2013.08.280

Liu, J., Head, E., Gharib, A. M., Yuan, W., Ingersoll, R. T., Hagen, T. M., et al. (2002). Memory loss in old rats is associated with brain mitochondrial decay and RNA/DNA oxidation: partial reversal by feeding acetyl-L-carnitine and/or
R-alpha -lipoic acid. Proc. Natl. Acad. Sci. U.S.A. 99, 2356-2361. doi: 10.1073/ pnas. 261709299

Livingston, G., Sommerlad, A., Orgeta, V., Costafreda, S. G., Huntley, J., Ames, D., et al. (2017). Dementia prevention, intervention, and care. Lancet 390, 2673 2734. doi: 10.1016/S0140-6736(17)31363-6

Lobos, P., Bruna, B., Cordova, A., Barattini, P., Galáz, J. L., Adasme, T., et al. (2016). Astaxanthin protects primary hippocampal neurons against noxious effects of A $\beta$-oligomers. Neural Plast. 2016, 3456783. doi: 10.1155/2016/3456783

Long, A. N., Owens, K., Schlappal, A. E., Kristian, T., Fishman, P. S., and Schuh, R. A. (2015). Effect of nicotinamide mononucleotide on brain mitochondrial respiratory deficits in an Alzheimer's disease-relevant murine model. BMC Neurol 15, 19. doi: 10.1186/s12883-015-0272-x

López-Lluch, G., Hunt, N., Jones, B., Zhu, M., Jamieson, H., Hilmer, S., et al. (2006). Calorie restriction induces mitochondrial biogenesis and bioenergetic efficiency. Proc. Natl. Acad. Sci. U.S.A. 103, 1768-1773. doi: 10.1073/ pnas. 0510452103

Loshchenova, P. S., Sinitsyna, O. I., Fedoseeva, L. A., Stefanova, N. A., and Kolosova, N. G. (2015). Influence of antioxidant SkQ1 on accumulation of mitochondrial DNA deletions in the hippocampus of senescence-accelerated OXYS rats. Biochem. Mosc. 80, 596-603. doi: 10.1134/S0006297915050120

Lovell, M. A., Xie, C., Xiong, S., and Markesbery, W. R. (2003). Protection against amyloid beta peptide and iron/hydrogen peroxide toxicity by alpha lipoic acid. J. Alzheimers Dis. 5, 229-239. doi: 10.3233/JAD-2003-5306

Lustbader, J. W., Cirilli, M., Lin, C., Xu, H. W., Takuma, K., Wang, N., et al. (2004). ABAD directly links Abeta to mitochondrial toxicity in Alzheimer's disease. Science 304, 448-452. doi: 10.1126/science.1091230

Manczak, M., Calkins, M. J., and Reddy, P. H. (2011). Impaired mitochondrial dynamics and abnormal interaction of amyloid beta with mitochondrial protein Drp1 in neurons from patients with Alzheimer's disease: implications for neuronal damage. Hum. Mol. Genet. 20, 2495-2509. doi: 10.1093/hmg/ ddr139

Manczak, M., Mao, P., Calkins, M. J., Cornea, A., Reddy, A. P., Murphy, M. P., et al. (2010). Mitochondria-targeted antioxidants protect against amyloid-beta toxicity in Alzheimer's disease neurons. J. Alzheimers Dis. 20 Suppl 2, S609S631. doi: 10.3233/JAD-2010-100564

Manczak, M., and Reddy, P. H. (2012). Abnormal interaction of VDAC1 with amyloid beta and phosphorylated tau causes mitochondrial dysfunction in Alzheimer's disease. Hum. Mol. Genet. 21 (23), 5131-46. doi: 10.1093/hmg/dds360.

Mangialasche, F., Baglioni, M., Cecchetti, R., Kivipelto, M., Ruggiero, C., Piobbico,D., et al. (2015). Lymphocytic mitochondrial aconitase activity is reduced in Alzheimer's disease and mild cognitive impairment. J. Alzheimers Dis. 44, 649660. doi: 10.3233/JAD-142052

Mao, P., Manczak, M., Calkins, M. J., Truong, Q., Reddy, T. P., Reddy, A. P., et al. (2012). Mitochondria-targeted catalase reduces abnormal APP processing, amyloid $\beta$ production and BACE1 in a mouse model of Alzheimer's disease: implications for neuroprotection and lifespan extension. Hum. Mol. Genet. 21, 2973-2990. doi: 10.1093/hmg/dds128

Marinelli, L., Fornasari, E., Di Stefano, A., Turkez, H., Arslan, M. E., Eusepi, P., et al. (2017). (R)- $\alpha$-Lipoyl-Gly-l-Pro-l-Glu dimethyl ester as dual acting agent for the treatment of Alzheimer's disease. Neuropeptides 66, 52-58. doi: 10.1016/j.npep.2017.09.001

Mark, R. J., Keller, J. N., Kruman, I., and Mattson, M. P. (1997). Basic FGF attenuates amyloid beta-peptide-induced oxidative stress, mitochondrial dysfunction, and impairment of $\mathrm{Na}+/ \mathrm{K}+$-ATPase activity in hippocampal neurons. Brain Res. 756, 205-214. doi: 10.1016/S0006-8993(97)00196-0

Martin, E. R., Lai, E. H., Gilbert, J. R., Rogala, A. R., Afshari, A. J., Riley, J., et al. (2000). SNPing away at complex diseases: analysis of single-nucleotide polymorphisms around APOE in Alzheimer disease. Am. J. Hum. Genet. 67, 383-394. doi: 10.1086/303003

Mattison, J. A., Colman, R. J., Beasley, T. M., Allison, D. B., Kemnitz, J. W., Roth, G.S., et al. (2017). Caloric restriction improves health and survival of rhesus monkeys. Nat. Commun. 8, 14063. doi: 10.1038/ncomms 14063

Maurer, I., Zierz, S., and Möller, H. J. (2000). A selective defect of cytochrome c oxidase is present in brain of Alzheimer disease patients. Neurobiol. Aging 21, 455-462. doi: 10.1016/S0197-4580(00)00112-3

McCormack, J. G., Halestrap, A. P., and Denton, R. M. (1990). Role of calcium ions in regulation of mammalian intramitochondrial metabolism. Physiol. Rev. 70, 391-425. doi: 10.1152/physrev.1990.70.2.391 
McManus, M. J., Murphy, M. P., and Franklin, J. L. (2011). The mitochondriatargeted antioxidant MitoQ prevents loss of spatial memory retention and early neuropathology in a transgenic mouse model of Alzheimer's disease. J. Neurosci. 31, 15703-15715. doi: 10.1523/JNEUROSCI.0552-11.2011

Medina, S., Martínez, M., and Hernanz, A. (2002). Antioxidants inhibit the human cortical neuron apoptosis induced by hydrogen peroxide, tumor necrosis factor alpha, dopamine and beta-amyloid peptide 1-42. Free Radic. Res. 36, 11791184. doi: $10.1080 / 107157602100006445$

Melov, S., Adlard, P. A., Morten, K., Johnson, F., Golden, T. R., Hinerfeld, D., et al. (2007). Mitochondrial oxidative stress causes hyperphosphorylation of tau. PLoS ONE 2, e536. doi: 10.1371/journal.pone.0000536

Mishra, P., and Chan, D. C. (2016). Metabolic regulation of mitochondrial dynamics. J. Cell Biol. 212, 379-387. doi: 10.1083/jcb.201511036

Moreira, P. I., Harris, P. L. R., Zhu, X., Santos, M. S., Oliveira, C. R., Smith, M. A., et al. (2007). Lipoic acid and $\mathrm{N}$-acetyl cysteine decrease mitochondrial-related oxidative stress in Alzheimer disease patient fibroblasts. J. Alzheimers Dis. 12, 195-206. doi: 10.3233/JAD-2007-12210

Moreira, P. I., Santos, M. S., Sena, C., Nunes, E., Seiça, R., and Oliveira, C. R. (2005). CoQ10 therapy attenuates amyloid beta-peptide toxicity in brain mitochondria isolated from aged diabetic rats. Exp. Neurol. 196, 112-119. doi: 10.1016/j.expneurol.2005.07.012

Morris, G. P., Clark, I. A., and Vissel, B. (2018). Questions concerning the role of amyloid- $\beta$ in the definition, aetiology and diagnosis of Alzheimer's disease. Acta Neuropathol. 136, 663-689. doi: 10.1007/s00401-018-1918-8

Morselli, E., Mariño, G., Bennetzen, M. V., Eisenberg, T., Megalou, E., Schroeder, S., et al. (2011). Spermidine and resveratrol induce autophagy by distinct pathways converging on the acetylproteome. J. Cell Biol. 192, 615-629. doi: 10.1083/ jcb. 201008167

Naga, K. K., and Geddes, J. W. (2011). Dimebon inhibits calcium-induced swelling of rat brain mitochondria but does not alter calcium retention or cytochrome $\mathrm{C}$ release. Neuromolecular Med. 13, 31-36. doi: 10.1007/s12017-010-8130-х

Ng, L. F., Gruber, J., Cheah, I. K., Goo, C. K., Cheong, W. F., Shui, G., et al. (2014). The mitochondria-targeted antioxidant MitoQ extends lifespan and improves healthspan of a transgenic Caenorhabditis elegans model of Alzheimer disease. Free Radic. Biol. Med. 71, 390-401. doi: 10.1016/j. freeradbiomed.2014.03.003

Nisoli, E., Tonello, C., Cardile, A., Cozzi, V., Bracale, R., Tedesco, L., et al. (2005). Calorie restriction promotes mitochondrial biogenesis by inducing the expression of eNOS. Science 310, 314-317. doi: 10.1126/science.1117728

Ochalek, A., Mihalik, B., Avci, H. X., Chandrasekaran, A., Téglási, A., Bock, I., et al. (2017). Neurons derived from sporadic Alzheimer's disease iPSCs reveal elevated TAU hyperphosphorylation, increased amyloid levels, and GSK3B activation. Alzheimers Res. Ther. 9, 90. doi: 10.1186/s13195-017-0317-z

Oksanen, M., Petersen, A. J., Naumenko, N., Puttonen, K., Lehtonen, Š., Gubert Olivé, M., et al. (2017). PSEN1 mutant iPSC-derived model reveals severe astrocyte pathology in Alzheimer's disease. Stem Cell. Rep. 9, 1885-1897. doi: 10.1016/j.stemcr.2017.10.016

Omar, S. H., Kerr, P. G., Scott, C. J., Hamlin, A. S., and Obied, H. K. (2017). Olive (Olea europaea L.) biophenols: a nutriceutical against oxidative stress in SH-SY5Y cells. Molecules 22, 1858. doi: 10.3390/molecules22111858

Ono, K., Hirohata, M., and Yamada, M. (2006). Alpha-lipoic acid exhibits antiamyloidogenicity for beta-amyloid fibrils in vitro. Biochem. Biophys. Res. Commun. 341, 1046-1052. doi: 10.1016/j.bbrc.2006.01.063

Owen, O. E., Morgan, A. P., Kemp, H. G., Sullivan, J. M., Herrera, M. G., and Cahill, G. F. (1967). Brain metabolism during fasting. J. Clin. Invest. 46, 15891595. doi: $10.1172 / J C I 105650$

Paillard, T., Rolland, Y., and de Souto Barreto, P. (2015). Protective effects of physical exercise in Alzheimer's disease and Parkinson's disease: a narrative review. J. Clin. Neurol. 11, 212-219. doi: 10.3988/jcn.2015.11.3.212

Pantano, D., Luccarini, I., Nardiello, P., Servili, M., Stefani, M., and Casamenti, F. (2017). Oleuropein aglycone and polyphenols from olive mill waste water ameliorate cognitive deficits and neuropathology. Br. J. Clin. Pharmacol. 83, 54-62. doi: 10.1111/bcp.12993

Pawlosky, R. J., Kemper, M. F., Kashiwaya, Y., King, M. T., Mattson, M. P., and Veech, R. L. (2017). Effects of a dietary ketone ester on hippocampal glycolytic and tricarboxylic acid cycle intermediates and amino acids in a $3 x T g A D$ mouse model of Alzheimer's disease. J. Neurochem. 141, 195-207. doi: 10.1111/ jnc. 13958
Payton, A., Sindrewicz, P., Pessoa, V., Platt, H., Horan, M., Ollier, W., et al. (2016). A TOMM40 poly-T variant modulates gene expression and is associated with vocabulary ability and decline in nonpathologic aging. Neurobiol. Aging 39, 217.e1-217.e7. doi: 10.1016/j.neurobiolaging.2015.11.017

Peng, T.-I., Hsiao, C.-W., Reiter, R. J., Tanaka, M., Lai, Y.-K., and Jou, M.-J. (2012). mtDNA T8993G mutation-induced mitochondrial complex V inhibition augments cardiolipin-dependent alterations in mitochondrial dynamics during oxidative, $\mathrm{Ca}(2+)$, and lipid insults in NARP cybrids: a potential therapeutic target for melatonin. J. Pineal. Res. 52, 93-106. doi: 10.1111/j.1600-079X.2011.00923.x

Peng, Y., Hou, C., Yang, Z., Li, C., Jia, L., Liu, J., et al. (2016). Hydroxytyrosol mildly improve cognitive function independent of APP processing in APP/PS1 mice. Mol. Nutr. Food Res. 60, 2331-2342. doi: 10.1002/mnfr.201600332

Perez Ortiz, J. M., and Swerdlow, R. H. (2019). Mitochondrial dysfunction in Alzheimer's disease: role in pathogenesis and novel therapeutic opportunities. Br. J. Pharmacol. 1-19 doi: 10.1111/bph.14585

Persson, T., Popescu, B. O., and Cedazo-Minguez, A. (2014). Oxidative stress in Alzheimer's disease: why did antioxidant therapy fail? Oxid. Med. Cell. Longev. 2014, 427318. doi: $10.1155 / 2014 / 427318$

Petrosillo, G., Moro, N., Ruggiero, F. M., and Paradies, G. (2009). Melatonin inhibits cardiolipin peroxidation in mitochondria and prevents the mitochondrial permeability transition and cytochrome c release. Free Radic. Biol. Med. 47, 969-974. doi: 10.1016/j.freeradbiomed.2009.06.032

Pfanner, N., Warscheid, B., and Wiedemann, N. (2019). Mitochondrial proteins: from biogenesis to functional networks. Nat. Rev. Mol. Cell Biol. 20, 267-284. doi: 10.1038/s41580-018-0092-0

Picca, A., Fracasso, F., Pesce, V., Cantatore, P., Joseph, A.-M., Leeuwenburgh, C., et al. (2013). Age- and calorie restriction-related changes in rat brain mitochondrial DNA and TFAM binding. Age (Dordr) 35, 1607-1620. doi: 10.1007/s11357-012-9465-z

Porquet, D., Griñán-Ferré, C., Ferrer, I., Camins, A., Sanfeliu, C., Del Valle, J., et al. (2014). Neuroprotective role of trans-resveratrol in a murine model of familial Alzheimer's disease. J. Alzheimers Dis. 42, 1209-1220. doi: 10.3233/ JAD-140444

Praticò, D., Clark, C. M., Liun, F., Rokach, J., Lee, V. Y.-M., and Trojanowski,J. Q. (2002). Increase of brain oxidative stress in mild cognitive impairment: a possible predictor of Alzheimer disease. Arch. Neurol. 59, 972-976. doi: 10.1001/archneur.59.6.972

Puchowicz, M. A., and Seyfried, T. N. (2017). Novel ketone body therapy for managing Alzheimer's disease: an editorial highlight for effects of a dietary ketone ester on hippocampal glycolytic and tricarboxylic acid cycle intermediates and amino acids in a 3xTgAD mouse model of Alzheimer's disease. J. Neurochem. 141, 162-164. doi: 10.1111/jnc.13979

Qin, W., Haroutunian, V., Katsel, P., Cardozo, C. P., Ho, L., Buxbaum, J. D., et al. (2009). PGC-1alpha expression decreases in the Alzheimer disease brain as a function of dementia. Arch. Neurol. 66, 352-361. doi: 10.1001/ archneurol.2008.588

Quinlan, C. L., Perevoshchikova, I. V., Hey-Mogensen, M., Orr, A. L., and Brand, M. D. (2013). Sites of reactive oxygen species generation by mitochondria oxidizing different substrates. Redox Biol. 1, 304-312. doi: 10.1016/ j.redox.2013.04.005

Quinn, J. F., Bussiere, J. R., Hammond, R. S., Montine, T. J., Henson, E., Jones, R. E., et al. (2007). Chronic dietary alpha-lipoic acid reduces deficits in hippocampal memory of aged Tg2576 mice. Neurobiol. Aging 28, 213-225. doi: 10.1016/j. neurobiolaging.2005.12.014

Reddy, C. A., Somepalli, V., Golakoti, T., Kanugula, A. K., Karnewar, S., Rajendiran, K., et al. (2014). Mitochondrial-targeted curcuminoids: a strategy to enhance bioavailability and anticancer efficacy of curcumin. PLoS ONE 9, e89351. doi: 10.1371/journal.pone.0089351

Reddy, P. H., Manczak, M., and Kandimalla, R. (2017). Mitochondria-targeted small molecule SS31: a potential candidate for the treatment of Alzheimer's disease. Hum. Mol. Genet. 26, 1597. doi: 10.1093/hmg/ddx129

Reddy, P. H., Manczak, M., Yin, X., Grady, M. C., Mitchell, A., Kandimalla, R., et al. (2016). Protective effects of a natural product, curcumin, against amyloid $\beta$ induced mitochondrial and synaptic toxicities in Alzheimer's disease. J. Investig. Med. 64, 1220-1234. doi: 10.1136/jim-2016-000240

Reddy, P. H., Manczak, M., Yin, X., and Reddy, A. P. (2018). Synergistic protective effects of mitochondrial division inhibitor 1 and mitochondria-targeted small 
peptide SS31 in Alzheimer's disease. J. Alzheimers Dis. 62, 1549-1565. doi: 10.3233/JAD-170988

Reed, T., Perluigi, M., Sultana, R., Pierce, W. M., Klein, J. B., Turner, D. M., et al. (2008). Redox proteomic identification of 4-hydroxy-2-nonenal-modified brain proteins in amnestic mild cognitive impairment: insight into the role of lipid peroxidation in the progression and pathogenesis of Alzheimer's disease. Neurobiol. Dis. 30, 107-120. doi: 10.1016/j.nbd.2007.12.007

Rege, S. D., Geetha, T., Broderick, T. L., and Babu, J. R. (2017). Can diet and physical activity limit Alzheimer's disease risk? Curr Alzheimer Res. 14, 76-93. doi: 10.2174/1567205013666160314145700

Remington, R., Bechtel, C., Larsen, D., Samar, A., Doshanjh, L., Fishman, P., et al. (2015). A phase II randomized clinical trial of a nutritional formulation for cognition and mood in Alzheimer's disease. J. Alzheimers Dis. 45, 395-405. doi: 10.3233/JAD-142499

Remington, R., Bechtel, C., Larsen, D., Samar, A., Page, R., Morrell, C., et al. (2016). Maintenance of cognitive performance and mood for individuals with Alzheimer's disease following consumption of a nutraceutical formulation: a one-year, open-label study. J. Alzheimers Dis. 51, 991-995. doi: 10.3233/ JAD-151098

Rhein, V., Giese, M., Baysang, G., Meier, F., Rao, S., Schulz, K. L., et al. (2010). Ginkgo biloba extract ameliorates oxidative phosphorylation performance and rescues abeta-induced failure. PLoS ONE 5, e12359. doi: 10.1371/journal. pone.0012359

Rinaldi, P., Polidori, M. C., Metastasio, A., Mariani, E., Mattioli, P., Cherubini, A., et al. (2003). Plasma antioxidants are similarly depleted in mild cognitive impairment and in Alzheimer's disease. Neurobiol. Aging 24, 915-919. doi: 10.1016/S0197-4580(03)00031-9

Ringman, J. M., Frautschy, S. A., Teng, E., Begum, A. N., Bardens, J., Beigi, M., et al. (2012). Oral curcumin for Alzheimer's disease: tolerability and efficacy in a 24-week randomized, double blind, placebo-controlled study. Alzheimers Res. Ther. 4, 43. doi: 10.1186/alzrt146

Rizzuto, R., and Pozzan, T. (2006). Microdomains of intracellular Ca2+: molecular determinants and functional consequences. Physiol. Rev. 86, 369-408. doi: 10.1152/physrev.00004.2005

Rosales-Corral, S. A., Lopez-Armas, G., Cruz-Ramos, J., Melnikov, V. G., Tan, D.-X., Manchester, L. C., et al. (2012a). Alterations in lipid levels of mitochondrial membranes induced by amyloid- $\beta$ : a protective role of melatonin. Int J. Alzheimers Dis. 2012, 459806. doi: 10.1155/2012/459806

Rosales-Corral, S., Acuna-Castroviejo, D., Tan, D. X., López-Armas, G., Cruz-Ramos, J., Munoz, R., et al. (2012b). Accumulation of exogenous amyloid-beta peptide in hippocampal mitochondria causes their dysfunction: a protective role for melatonin. Oxid. Med. Cell. Longev. 2012, 843649. doi: 10.1155/2012/843649

Roses, A. D., Lutz, M. W., Amrine-Madsen, H., Saunders, A. M., Crenshaw, D. G., Sundseth, S. S., et al. (2010). A TOMM40 variable-length polymorphism predicts the age of late-onset Alzheimer's disease. Pharmacogenomics J. 10, 375-384. doi: 10.1038/tpj.2009.69

Rüb, C., Wilkening, A., and Voos, W. (2017). Mitochondrial quality control by the Pink1/Parkin system. Cell. Tissue Res. 367, 111-123. doi: 10.1007/ s00441-016-2485-8

Rudnitskaya, E. A., Muraleva, N. A., Maksimova, K. Y., Kiseleva, E., Kolosova, N. G., and Stefanova, N. A. (2015). Melatonin attenuates memory impairment, amyloid- $\beta$ accumulation, and neurodegeneration in a rat model of sporadic Alzheimer's disease. J. Alzheimers Dis. 47, 103-116. doi: 10.3233/JAD-150161

Rui, Y., Tiwari, P., Xie, Z., and Zheng, J. Q. (2006). Acute impairment of mitochondrial trafficking by beta-amyloid peptides in hippocampal neurons. J. Neurosci. 26, 10480-10487. doi: 10.1523/JNEUROSCI.3231-06.2006

Russo, G. J., Louie, K., Wellington, A., Macleod, G. T., Hu, F., Panchumarthi, S., et al. (2009). Drosophila Miro is required for both anterograde and retrograde axonal mitochondrial transport. J. Neurosci. 29, 5443-5455. doi: 10.1523/ JNEUROSCI.5417-08.2009

Ryu, D., Mouchiroud, L., Andreux, P. A., Katsyuba, E., Moullan, N., Nicolet-DitFélix, A. A., et al. (2016). Urolithin A induces mitophagy and prolongs lifespan in C. elegans and increases muscle function in rodents. Nat. Med. 22, 879-888. doi: $10.1038 / \mathrm{nm} .4132$

Sadli, N., Barrow, C. J., McGee, S., and Suphioglu, C. (2013). Effect of DHA and coenzymeQ10 against $\mathrm{A} \beta$ - and zinc-induced mitochondrial dysfunction in human neuronal cells. Cell. Physiol. Biochem. 32, 243-252. doi: $10.1159 / 000354433$
Sancheti, H., Akopian, G., Yin, F., Brinton, R. D., Walsh, J. P., and Cadenas, E. (2013). Age-dependent modulation of synaptic plasticity and insulin mimetic effect of lipoic acid on a mouse model of Alzheimer's disease. PLOS ONE 8, e69830. doi: 10.1371/journal.pone.0069830

Sanchis-Gomar, F., García-Giménez, J. L., Gómez-Cabrera, M. C., and Pallardó, F. V. (2014). Mitochondrial biogenesis in health and disease. molecular and therapeutic approaches. Curr. Pharm. Des. 20, 5619-5633. doi: 10.2174/1381 612820666140306095106

Saunders, A. M., Strittmatter, W. J., Schmechel, D., George-Hyslop, P. H., PericakVance, M. A., Joo, S. H., et al. (1993). Association of apolipoprotein E allele epsilon 4 with late-onset familial and sporadic Alzheimer's disease. Neurology 43, 1467-1472. doi: 10.1212/WNL.43.8.1467

Scarmeas, N., Stern, Y., Tang, M.-X., Mayeux, R., and Luchsinger, J. A. (2006). Mediterranean diet and risk for Alzheimer's disease. Ann. Neurol. 59, 912-921. doi: 10.1002/ana.20854

Scarpulla, R. C. (2011). Metabolic control of mitochondrial biogenesis through the PGC-1 family regulatory network. Biochim. Biophys. Acta 1813, 1269-1278. doi: 10.1016/j.bbamcr.2010.09.019

Schloesser, A., Esatbeyoglu, T., Piegholdt, S., Dose, J., Ikuta, N., Okamoto, H., et al. (2015). Dietary tocotrienol $/ \gamma$-cyclodextrin complex increases mitochondrial membrane potential and ATP concentrations in the brains of aged mice. Oxid. Med. Cell. Longev. 2015, 789710. doi: 10.1155/2015/789710

Schroeder, E. K., Kelsey, N. A., Doyle, J., Breed, E., Bouchard, R. J., Loucks, F. A., et al. (2009). Green tea epigallocatechin 3-gallate accumulates in mitochondria and displays a selective antiapoptotic effect against inducers of mitochondrial oxidative stress in neurons. Antioxid. Redox Signal 11, 469-480. doi: 10.1089/ ars.2008.2215

Selvaraju, T. R., Khazảai, H., Vidyadaran, S., Abd Mutalib, M. S., and Vasudevan, R. (2014). The neuroprotective effects of tocotrienol rich fraction and alpha tocopherol against glutamate injury in astrocytes. Bosn. J. Basic Med. Sci. 14, 195-204. doi: 10.17305/bjbms.2014.4.91

Serafini, M. M., Catanzaro, M., Rosini, M., Racchi, M., and Lanni, C. (2017). Curcumin in Alzheimer's disease: can we think to new strategies and perspectives for this molecule? Pharmacol. Res. 124, 146-155. doi: 10.1016/j. phrs.2017.08.004

Shariff, K., Ghosal, S., and Matouschek, A. (2004). The force exerted by the membrane potential during protein import into the mitochondrial matrix. Biophys. J. 86, 3647-3652. doi: 10.1529/biophysj.104.040865

Sharma, D. R., Wani, W. Y., Sunkaria, A., Kandimalla, R. J., Sharma, R. K., Verma, D., et al. (2016). Quercetin attenuates neuronal death against aluminum-induced neurodegeneration in the rat hippocampus. Neuroscience 324, 163-176. doi: 10.1016/j.neuroscience.2016.02.055

Sheng, B., Wang, X., Su, B., Lee, H., Casadesus, G., Perry, G., et al. (2012). Impaired mitochondrial biogenesis contributes to mitochondrial dysfunction in Alzheimer's disease. J. Neurochem. 120, 419-429. doi: 10.1111/j.1471-4159.2011.07581.x

Sheng, Z.-H., and Cai, Q. (2012). Mitochondrial transport in neurons: impact on synaptic homeostasis and neurodegeneration. Nat. Rev. Neurosci. 13, 77-93. doi: $10.1038 / \mathrm{nrn} 3156$

Shukla, M., Govitrapong, P., Boontem, P., Reiter, R. J., and Satayavivad, J. (2017). Mechanisms of melatonin in alleviating Alzheimer's disease. Curr. Neuropharmacol. 15, 1010-1031. doi: 10.2174/1570159X15666170313123454

Smith, R. A. J., Porteous, C. M., Gane, A. M., and Murphy, M. P. (2003). Delivery of bioactive molecules to mitochondria in vivo. Proc. Natl. Acad. Sci. U.S.A. 100, 5407-5412. doi: 10.1073/pnas.0931245100

Snitz, B. E., O’Meara, E. S., Carlson, M. C., Arnold, A. M., Ives, D. G., Rapp, S. R., et al. (2009). Ginkgo biloba for preventing cognitive decline in older adults: a randomized trial. JAMA 302, 2663-2670. doi: 10.1001/jama.2009.1913

Song, C., Li, M., Xu, L., Shen, Y., Yang, H., Ding, M., et al. (2018). Mitochondrial biogenesis mediated by melatonin in an APswe/PS1dE9 transgenic mice model. Neuroreport 29, 1517-1524. doi: 10.1097/WNR.0000000000001139

Sood, P. K., Nahar, U., and Nehru, B. (2011). Curcumin attenuates aluminuminduced oxidative stress and mitochondrial dysfunction in rat brain. Neurotox Res. 20, 351-361. doi: 10.1007/s12640-011-9249-8

Spilman, P., Podlutskaya, N., Hart, M. J., Debnath, J., Gorostiza, O., Bredesen, D., et al. (2010). Inhibition of mTOR by rapamycin abolishes cognitive deficits and reduces amyloid-beta levels in a mouse model of Alzheimer's disease. PLoS ONE 5, e9979. doi: 10.1371/journal.pone.0009979 
Stefanova, N. A., Muraleva, N. A., Maksimova, K. Y., Rudnitskaya, E. A., Kiseleva, E., Telegina, D. V., et al. (2016). An antioxidant specifically targeting mitochondria delays progression of Alzheimer's disease-like pathology. Aging (Albany NY) 8, 2713-2733. doi: 10.18632/aging.101054

Stock, D., Gibbons, C., Arechaga, I., Leslie, A. G., and Walker, J. E. (2000). The rotary mechanism of ATP synthase. Curr. Opin. Struct. Biol. 10, 672-679. doi: 10.1016/S0959-440X(00)00147-0

Studer, R., Baysang, G., and Brack, C. (2001). N-Acetyl-L-cystein downregulates beta-amyloid precursor protein gene transcription in human neuroblastoma cells. Biogerontology 2, 55-60. doi: 10.1023/A:1010065103073

Subramanian, S., Gottschalk, W. K., Kim, S. Y., Roses, A. D., and Chiba-Falek, O. (2017). The effects of PPAR $\gamma$ on the regulation of the TOMM40-APOE-C1 genes cluster. Biochim Biophys Acta Mol Basis Dis 1863, 810-816. doi: 10.1016/j. bbadis.2017.01.004

Sultana, R., Poon, H. F., Cai, J., Pierce, W. M., Merchant, M., Klein, J. B., et al. (2006). Identification of nitrated proteins in Alzheimer's disease brain using a redox proteomics approach. Neurobiol. Dis. 22, 76-87. doi: 10.1016/j. nbd.2005.10.004

Swerdlow, R. H., Bothwell, R., Hutfles, L., Burns, J. M., and Reed, G. A. (2016). Tolerability and pharmacokinetics of oxaloacetate $100 \mathrm{mg}$ capsules in Alzheimer's subjects. BBA Clin. 5, 120-123. doi: 10.1016/j.bbacli.2016.03.005

Swerdlow, R. H., Burns, J. M., and Khan, S. M. (2014). The Alzheimer's disease mitochondrial cascade hypothesis: progress and perspectives. Biochim. Biophys. Acta 1842, 1219-1231. doi: 10.1016/j.bbadis.2013.09.010

Swerdlow, R. H., and Khan, S. M. (2004). A "mitochondrial cascade hypothesis" for sporadic Alzheimer's disease. Med. Hypotheses 63, 8-20. doi: 10.1016/j. mehy.2003.12.045

Szeto, H. H. (2006). Cell-permeable, mitochondrial-targeted, peptide antioxidants. AAPS J. 8, E277-E283. doi: 10.1208/aapsj080232

Taguchi, N., Ishihara, N., Jofuku, A., Oka, T., and Mihara, K. (2007). Mitotic phosphorylation of dynamin-related GTPase Drp1 participates in mitochondrial fission. J. Biol. Chem. 282, 11521-11529. doi: 10.1074/jbc. M607279200

Takei, N., Miyashita, A., Tsukie, T., Arai, H., Asada, T., Imagawa, M., et al. (2009). Genetic association study on in and around the APOE in late-onset Alzheimer disease in Japanese. Genomics 93, 441-448. doi: 10.1016/j.ygeno.2009.01.003

Taylor, M. K., Sullivan, D. K., Mahnken, J. D., Burns, J. M., and Swerdlow, R. H. (2018). Feasibility and efficacy data from a ketogenic diet intervention in Alzheimer's disease. Alzheimers Dement. (N Y) 4, 28-36. doi: 10.1016/j. trci.2017.11.002

Taylor, M. K., Swerdlow, R. H., Burns, J. M., and Sullivan, D. K. (2019). An experimental ketogenic diet for Alzheimer disease was nutritionally dense and rich in vegetables and avocado. Curr. Dev. Nutr. 3, nzz003. doi: 10.1093/cdn/ nzz003

Tian, X., Zhang, L., Wang, J., Dai, J., Shen, S., Yang, L., et al. (2013). The protective effect of hyperbaric oxygen and Ginkgo biloba extract on A 325 -35-induced oxidative stress and neuronal apoptosis in rats. Behav. Brain Res. 242, 1-8. doi: 10.1016/j.bbr.2012.12.026

Traber, J., Suter, M., Walter, P., and Richter, C. (1992). In vivo modulation of total and mitochondrial glutathione in rat liver. Depletion by phorone and rescue by $\mathrm{N}$-acetylcysteine. Biochem. Pharmacol. 43, 961-964. doi: 10.1016/0006-2952(92)90599-E

Tramutola, A., Abate, G., Lanzillotta, C., Triani, F., Barone, E., Iavarone, F., et al. (2018). Protein nitration profile of CD3+ lymphocytes from Alzheimer disease patients: novel hints on immunosenescence and biomarker detection. Free Radic. Biol. Med. 129, 430-439. doi: 10.1016/j.freeradbiomed.2018.10.414

Valenti, D., De Rasmo, D., Signorile, A., Rossi, L., de Bari, L., Scala, I., et al. (2013). Epigallocatechin-3-gallate prevents oxidative phosphorylation deficit and promotes mitochondrial biogenesis in human cells from subjects with Down's syndrome. Biochim. Biophys. Acta 1832, 542-552. doi: 10.1016/j. bbadis.2012.12.011

Veitch, D. P., Weiner, M. W., Aisen, P. S., Beckett, L. A., Cairns, N. J., Green, R. C., et al. (2019). Understanding disease progression and improving Alzheimer's disease clinical trials: recent highlights from the Alzheimer's disease neuroimaging initiative. Alzheimers Dement. 15, 106-152. doi: 10.1016/j. jalz.2018.08.005

Vellas, B., Coley, N., Ousset, P.-J., Berrut, G., Dartigues, J.-F., Dubois, B., et al. (2012). Long-term use of standardised Ginkgo biloba extract for the prevention of Alzheimer's disease (GuidAge): a randomised placebo-controlled trial. Lancet Neurol. 11, 851-859. doi: 10.1016/S1474-4422(12)70206-5

Verstreken, P., Ly, C. V., Venken, K. J. T., Koh, T.-W., Zhou, Y., and Bellen, H. J. (2005). Synaptic mitochondria are critical for mobilization of reserve pool vesicles at Drosophila neuromuscular junctions. Neuron 47, 365-378. doi: 10.1016/j.neuron.2005.06.018

Vidoni, E. D., Johnson, D. K., Morris, J. K., Van Sciver, A., Greer, C. S., Billinger, S. A., et al. (2015). Dose-response of aerobic exercise on cognition: a communitybased, pilot randomized controlled trial. PLoS ONE 10, e0131647. doi: 10.1371/ journal.pone.0131647

Vinceti, M., Mandrioli, J., Borella, P., Michalke, B., Tsatsakis, A., and Finkelstein, Y. (2014). Selenium neurotoxicity in humans: bridging laboratory and epidemiologic studies. Toxicol. Lett. 230, 295-303. doi: 10.1016/j. toxlet.2013.11.016

Voos, W. (2013). Chaperone-protease networks in mitochondrial protein homeostasis. Biochim. Biophys. Acta 1833, 388-399. doi: 10.1016/j. bbamcr.2012.06.005

Wang, C.-F., Song, C.-Y., Wang, X., Huang, L.-Y., Ding, M., Yang, H., et al. (2019). Protective effects of melatonin on mitochondrial biogenesis and mitochondrial structure and function in the HEK293-APPswe cell model of Alzheimer's disease. Eur. Rev. Med. Pharmacol. Sci. 23, 3542-3550. doi: 10.26355/ eurrev_201904_17723

Wang, D.-M., Li, S.-Q., Wu, W.-L., Zhu, X.-Y., Wang, Y., and Yuan, H.-Y. (2014). Effects of long-term treatment with quercetin on cognition and mitochondrial function in a mouse model of Alzheimer's disease. Neurochem. Res. 39, 1533 1543. doi: 10.1007/s11064-014-1343-x

Wang, H., Jiang, T., Li, W., Gao, N., and Zhang, T. (2018). Resveratrol attenuates oxidative damage through activating mitophagy in an in vitro model of Alzheimer's disease. Toxicol. Lett. 282, 100-108. doi: 10.1016/j. toxlet.2017.10.021

Wang, J., Markesbery, W. R., and Lovell, M. A. (2006). Increased oxidative damage in nuclear and mitochondrial DNA in mild cognitive impairment. J. Neurochem. 96, 825-832. doi: 10.1111/j.1471-4159.2005.03615.x

Wang, W., Yin, J., Ma, X., Zhao, F., Siedlak, S. L., Wang, Z., et al. (2017). Inhibition of mitochondrial fragmentation protects against Alzheimer's disease in rodent model. Hum. Mol. Genet. 26, 4118-4131. doi: 10.1093/hmg/ddx299

Wang, X., Hu, X., Yang, Y., Takata, T., and Sakurai, T. (2016). Nicotinamide mononucleotide protects against $\beta$-amyloid oligomer-induced cognitive impairment and neuronal death. Brain Res. 1643, 1-9. doi: 10.1016/j. brainres.2016.04.060

Wang, X., Su, B., Fujioka, H., and Zhu, X. (2008a). Dynamin-like protein 1 reduction underlies mitochondrial morphology and distribution abnormalities in fibroblasts from sporadic Alzheimer's disease patients. Am. J. Pathol. 173, 470-482. doi: 10.2353/ajpath.2008.071208

Wang, X., Su, B., Siedlak, S. L., Moreira, P. I., Fujioka, H., Wang, Y., et al. (2008b). Amyloid-beta overproduction causes abnormal mitochondrial dynamics via differential modulation of mitochondrial fission/fusion proteins. Proc. Natl. Acad. Sci. U.S.A. 105, 19318-19323. doi: 10.1073/pnas.0804871105

Wang, X., Su, B., Lee, H., Li, X., Perry, G., Smith, M. A., et al. (2009). Impaired balance of mitochondrial fission and fusion in Alzheimer's disease. J. Neurosci. 29, 9090-9103. doi: 10.1523/JNEUROSCI.1357-09.2009

Weisová, P., Alvarez, S. P., Kilbride, S. M., Anilkumar, U., Baumann, B., Jordán, J., et al. (2013). Latrepirdine is a potent activator of AMP-activated protein kinase and reduces neuronal excitability. Transl Psychiatry 3, e317. doi: 10.1038/ tp. 2013.92

Werth, J. L., and Thayer, S. A. (1994). Mitochondria buffer physiological calcium loads in cultured rat dorsal root ganglion neurons. J. Neurosci. 14, 348-356. doi: 10.1523/JNEUROSCI.14-01-00348.1994

Wilkins, H. M., and Morris, J. K. (2017). New therapeutics to modulate mitochondrial function in neurodegenerative disorders. Curr. Pharm. Des. 23, 731-752. doi: $10.2174 / 1381612822666161230144517$

Wilkins, H. M., Harris, J. L., Carl, S. M., L, E., Lu, J., Eva Selfridge, J., et al. (2014). Oxaloacetate activates brain mitochondrial biogenesis, enhances the insulin pathway, reduces inflammation and stimulates neurogenesis. Hum. Mol. Genet. 23, 6528-6541. doi: 10.1093/hmg/ddu371

Wojsiat, J., Prandelli, C., Laskowska-Kaszub, K., Martín-Requero, A., and Wojda, U. (2015). Oxidative stress and aberrant cell cycle in Alzheimer's disease lymphocytes: diagnostic prospects. J. Alzheimers Dis. 46, 329-350. doi: 10.3233/JAD-141977 
Xue, Z., Guo, Y., and Fang, Y. (2016). Moderate activation of autophagy regulates the intracellular calcium ion concentration and mitochondrial membrane potential in beta-amyloid-treated PC12 cells. Neurosci. Lett. 618, 50-57. doi: 10.1016/j.neulet.2016.02.044

Yao, J., Chen, S., Mao, Z., Cadenas, E., and Brinton, R. D. (2011). 2-Deoxy-Dglucose treatment induces ketogenesis, sustains mitochondrial function, and reduces pathology in female mouse model of Alzheimer's disease. PLoS ONE 6, e21788. doi: 10.1371/journal.pone.0021788

Yao, J., Irwin, R. W., Zhao, L., Nilsen, J., Hamilton, R. T., and Brinton, R. D. (2009). Mitochondrial bioenergetic deficit precedes Alzheimer's pathology in female mouse model of Alzheimer's disease. Proc. Natl. Acad. Sci. U.S.A. 106, 1467014675. doi: 10.1073/pnas.0903563106

Yi, M., Weaver, D., and Hajnóczky, G. (2004). Control of mitochondrial motility and distribution by the calcium signal: a homeostatic circuit. J. Cell Biol. 167, 661-672. doi: 10.1083/jcb.200406038

Yokoyama, H., Okazaki, K., Imai, D., Yamashina, Y., Takeda, R., Naghavi, N., et al. (2015). The effect of cognitive-motor dual-task training on cognitive function and plasma amyloid $\beta$ peptide $42 / 40$ ratio in healthy elderly persons: a randomized controlled trial. BMC Geriatr 15, 60. doi: 10.1186/ s12877-015-0058-4

Youle, R. J., and Narendra, D. P. (2011). Mechanisms of mitophagy. Nat. Rev. Mol. Cell Biol. 12, 9-14. doi: 10.1038/nrm3028
Zhang, S., Hedskog, L., Petersen, C. A. H., Winblad, B., and Ankarcrona, M. (2010). Dimebon (latrepirdine) enhances mitochondrial function and protects neuronal cells from death. J. Alzheimers Dis. 21, 389-402. doi: 10.3233/ JAD-2010-100174

Zhang, Z.-X., Li, Y.-B., and Zhao, R.-P. (2017). Epigallocatechin gallate attenuates $\beta$-amyloid generation and oxidative stress involvement of PPAR $\gamma$ in N2a/ APP695 cells. Neurochem. Res. 42, 468-480. doi: 10.1007/s11064-016-2093-8

Zhao, X.-L., Wang, W.-A., Tan, J.-X., Huang, J.-K., Zhang, X., Zhang, B.-Z., et al. (2010). Expression of beta-amyloid induced age-dependent presynaptic and axonal changes in Drosophila. J. Neurosci. 30, 1512-1522. doi: 10.1523/ JNEUROSCI.3699-09.2010

Conflict of Interest Statement: The authors declare that the research was conducted in the absence of any commercial or financial relationships that could be construed as a potential conflict of interest.

Copyright (c) 2019 Cenini and Voos. This is an open-access article distributed under the terms of the Creative Commons Attribution License (CC BY). The use, distribution or reproduction in other forums is permitted, provided the original author(s) and the copyright owner(s) are credited and that the original publication in this journal is cited, in accordance with accepted academic practice. No use, distribution or reproduction is permitted which does not comply with these terms. 